\title{
Review
}

\section{Omics in major cereals: applications, challenges, and prospects}

\author{
Balwinder Kaur ${ }^{1,+}{ }^{\dagger}$, Karansher S. Sandhu ${ }^{2,+}$, Roop Kamal ${ }^{3}$, Kawalpreet Kaur ${ }^{4}$, Jagmohan Singh ${ }^{5}$, \\ Marion S. Röder ${ }^{3}$, and Quddoos H. Muqaddasi 3,6,*
}

1 Everglades Research and Education Center, University of Florida, Institute of Food and Agricultural Sciences, 3200 E. Palm Beach Rd., Belle Glade, FL, USA, 33430; bkaur@ufl.edu (B.K.)

2 Department of Crop and Soil Sciences, Washington State University, Pullman, WA, USA, 99163; k.sandhu@wsu.edu (K.S.S.)

3 Leibniz Institute of Plant Genetics and Crop Plant Research (IPK), Corrensstraße 3, D-06466 Stadt Seeland OT Gatersleben, Germany; kamal@ipk-gatersleben.de (R.K.), roder@ipk-gatersleben.de (M.S.R.)

4 Department of Agricultural, Food and Nutritional Science, University of Alberta, Edmonton, Alberta, T6G 2P5, Canada; kawalpre@ualberta.ca (K.K.)

5 Division of Plant Pathology, ICAR-Indian Agricultural Research Institute, New Delhi-110012, India; Iagmohan 11307@iari.res.in (J.S.)

6 Present address: European Wheat Breeding Center, BASF Agricultural Solutions GmbH, Am Schwabeplan 8, D-06466 Stadt Seeland OT Gatersleben, Germany.

$+\quad$ The authors contributed equally in this manuscript.

* Correspondence: muqaddasi@ipk-gatersleben.de; (Q.H.M.)

Simple Summary: Omics, as a set of technologies, viz., genomics, transcriptomics, proteomics, metabolomics, and phenomics, have substantially helped the crop improvement landscape. Here, we review omics' applications and prospects in five major cereals, viz., rice, sorghum, maize, barley, and bread wheat. In Figure 1, we describe how these technologies have evolved to keep pace with crop improvement programs focusing on breeding applications. We section this review according to the technologies mentioned above and, in every section, describe their applications in cereals.

\begin{abstract}
Omics technologies, viz., genomics, transcriptomics, proteomics, metabolomics, and phenomics, are becoming an integral part of virtually every commercial cereal breeding program because they provide substantial dividends per unit time in both pre-breeding and breeding phases. Continuous advances in cereal-omics promise-in combination with time efficiency - the cost benefits. In this review, we provide a comprehensive overview of the established cereal-omics methods in five major cereals, viz., rice, sorghum, maize, barley, and bread wheat. We cover the evolution of technologies in each omics section independently and concentrate on their use to improve economically important agronomic as well as biotic and abiotic stress-related traits. Advancements in the (1) identification, mapping, and sequencing of molecular/structural variants, (2) high-density transcriptomics data to study gene expression patterns, (3) global and targeted proteome profiling to study protein structure and interaction, (4) metabolomic profiling to quantify organ level smalldensity metabolites and their composition, and (5) high-resolution high-throughput image-based phenomics approaches are surveyed in this review.
\end{abstract}




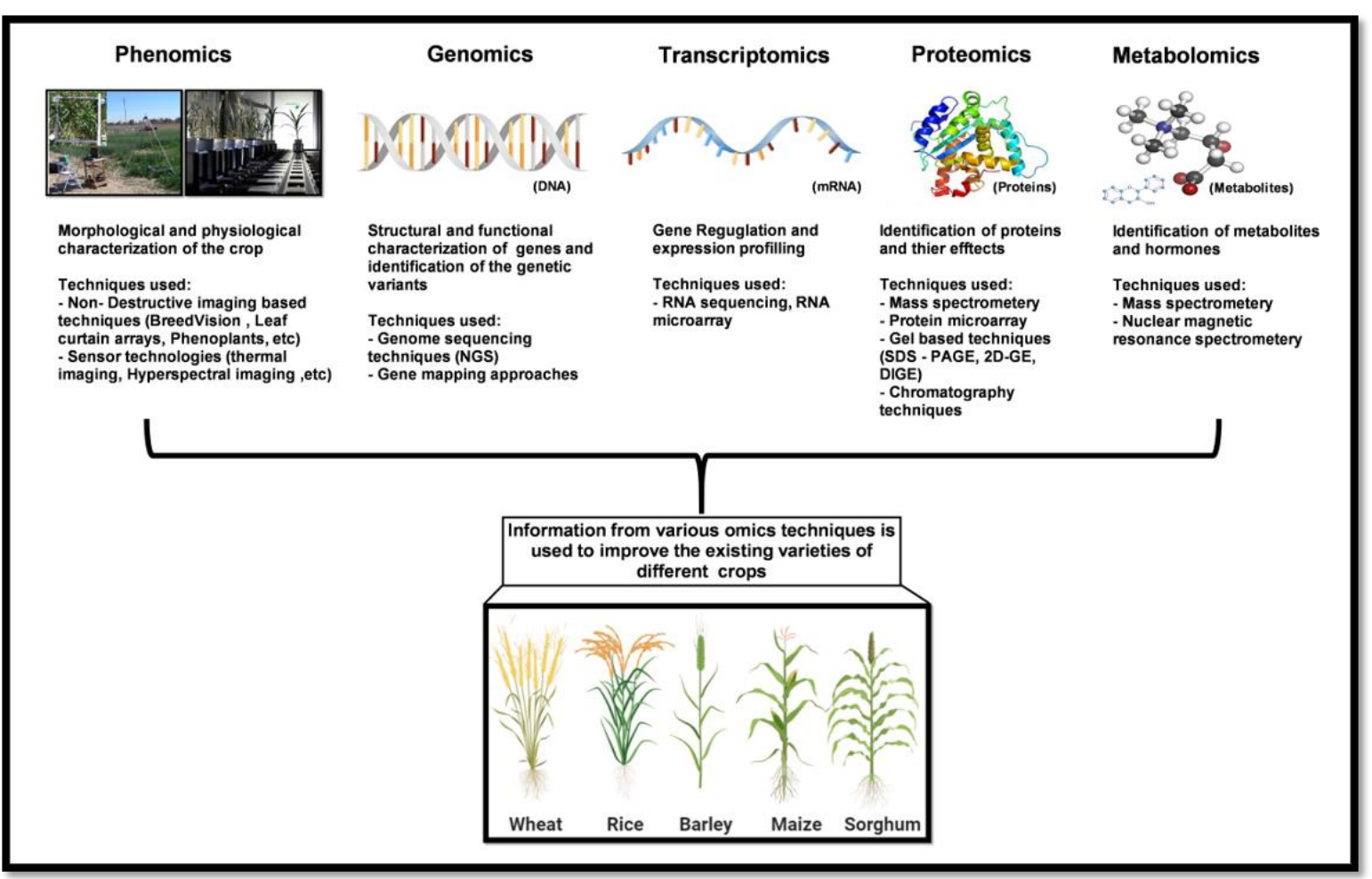

Figure 1. An overview of the use of "omics" in cereal improvement.

Keywords: cereals; omics; gemomics; transcriptomics; proteomics; metabolomics; phenomics.

\section{Cereal genomics: evolution from sparse genetic markers to whole-genome sequenc- ing}

Identification of molecular markers, i.e., the observable polymorphisms among individuals of a population within a given DNA sequence, laid the foundations of modern genomics. In the 1980s, the detection of restriction fragment length polymorphisms (RFLPs) and their subsequent association with several primary agronomic importance traits forecasted the promises of genomics to improve the genetic gain per unit time. Later, many other marker systems - most notably microsatellite or simple sequence repeat (SSR) markers - were used to map quantitative trait loci (QTLs). Nevertheless, albeit their excellent use in locating the polymorphisms and use in applied breeding, these systems were time- and cost-inefficient and low throughput. For example, the first SSR map of wheat harbored only 279 loci [1]. Most economically important traits, e.g., grain yield, disease resistance, and grain protein content, are polygenic, i.e., they are controlled by the concerted action of several small- to medium-effect genetic loci [2]. Therefore, sparse genetic linkage maps harboring a limited number of genetic loci become inefficient for improving highly complex or quantitative traits mainly because of the trait-linked loci's absence.

Detection of single nucleotide polymorphisms (SNPs) - the smallest unit of DNA polymorphism - provides an opportunity to survey virtually millions of sites within a species' DNA. Thus, it has become a marker platform of choice. High-throughput, highefficiency, reproducibility, and low cost per data point have enabled large-scale germplasm evaluations in many cereals and, consequently, have resulted in the almost complete replacement of RFLPs or SSR marker platforms [3]. Major methods for SNP detection in cereals include array-based genotyping and genotyping-by-sequencing. Several sequencing technologies are available for both forms of SNP detection [3]. High-density SNP genotyping is invaluable for identifying the genetic underpinning of economically relevant traits and laying the foundation of whole-genome sequencing. 
While whole-genome sequencing for hundreds of animal species had already been reported, it is only recently that the genomes of major cereals were fully sequenced (available online at NCBI). The technological innovations coupled with international collaborative consortia efforts have led to the construction of cereal genome assemblies that may be used for several applied genetic purposes, e.g., genome-wide scans for genes controlling essential traits. However, sequencing of cereal genomes has particularly been challenging mainly because of their large sizes and abundance of repetitive sequences [4]. Three of the major cereals, viz., rice (Oryza sativa L.), sorghum (Sorghum bicolor L.), and maize (Zea mays L.), have been very well-sequenced using various technologies - the foremost reason being their diploid nature and small genomes. For example, primarily because of limited genome size and diploid nature, rice became a model choice for the whole-genome sequencing, and in 2002 working genome drafts of domesticated rice subspecies (ssp. japonica and indica) were published [5,6]. Following rice, seven years later, sorghum and maize genomes were published $[7,8]$. Barley (Hordeum vulgare L.) and bread wheat-among the most important members of the Triticieae tribe-were difficult to sequence mainly because of their large genome sizes (Figure 2). The first draft assembly of barley (cultivar Morex) - released in 2012-was assembled based on genome-zipper, whole genome shotgun (WGS) contigs, and bacterial artificial chromosomes (BAC) clones (TIBGSC 2012). Bread wheat genome assembly was complicated primarily because of its polyploid nature and its genome size that is more than three times that of barley. In 2014, the first wheat genome draft assembly based on chromosome sorted WGS sequences were released by the IWGSC.
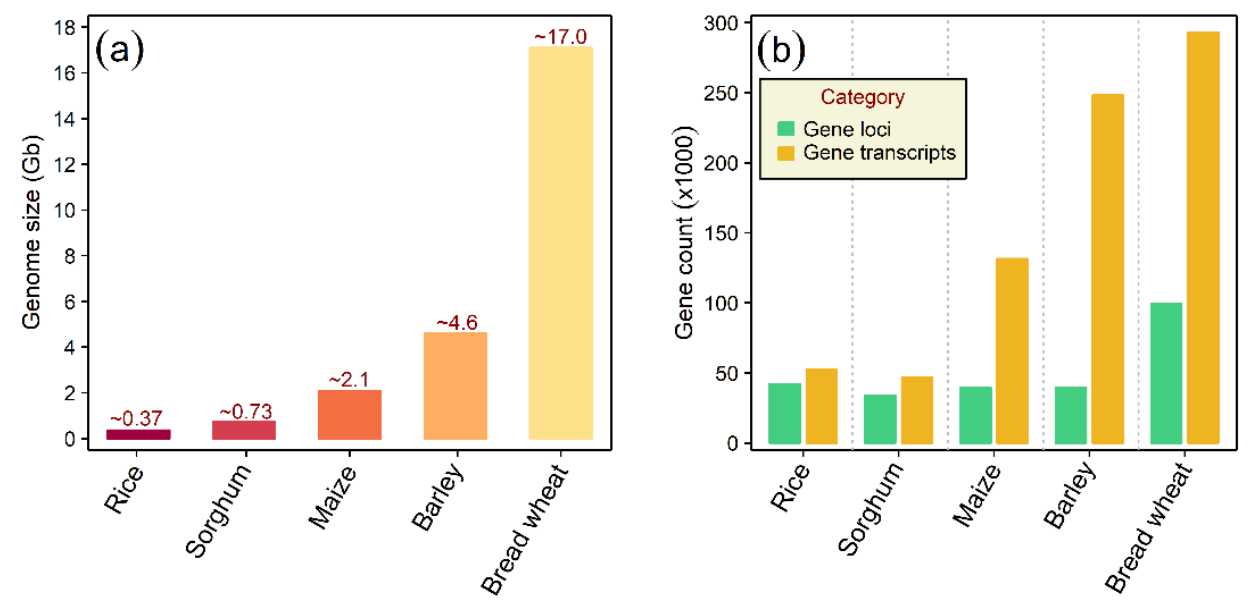

Figure 2. Cereal genome features. (a) An approximate genome size in Gb and (b) genetic loci and the transcripts harbored by top production cereals. The data is mainly gathered from the "Phytozome" website (https://phytozome-next.jgi.doe.gov/), and the references to each sequence are given in the main text.

\subsection{Types of genomic variants: applications in genetics and breeding}

Every applied plant breeding program's success hinges on artificial selection-a process that involves the selection, preservation, and propagation of plants possessing the most desirable characters from a diverse population. Artificial selection is determined by the considerable genotypic variation in a population that results in high heritability of the traits under selection. Variation, and in this case, genotypic variation, is a type of variation that is directly ascribed to the genetic differences among individuals of a given population. Therefore, genomics can help to improve crops because it assesses the genetic or genomic polymorphisms among individuals.

Differences in the plant species mainly arise due to the structural variations within its genome. These structural variations vary significantly in size ranging from SNP to more gigantic insertions, deletions, copy number variations, etc. Some of these variants are described below as well as in Fig. 3. 


\subsubsection{Single nucleotide polymorphisms (SNPs)}

As described elsewhere, with the high-throughput and cost-effective sequencing, it is relatively easier to discover millions of SNPs in a plant species. SNPs are frequently found in the genomes and primarily lay the foundations of the genetic diversity among individuals of a given population. Both coding and non-coding regions of the genome can harbor SNPs that can alter the expression profile. Therefore, uncovering the functional SNPs in gene/s and finding their effects on the phenotype can help to understand the gene function and, subsequently, its product.

Rice-along with other cereals - presents one example to showcase SNPs' abundant nature. Approximately 20 million SNPs were discovered by aligning the resequencing results for $\sim 3,000$ rice genomes (3k RG) against the Nipponbare reference sequence [9]. SNPs' use in cereal breeding programs is indisputable where high density genotyping resulted in associations of SNPs with several traits of central agronomic value via linkage mapping and genome-wide association studies (GWAS).

\subsubsection{Variants apart from SNPs}

While SNPs are an essential source for identifying and mapping traits of interests, studies show that "only" SNPs do not represent all the genomic variation that contributes to the resulting phenotype, and, therefore, other variants, e.g., structural variations (SVs) - that may be up to 1-kb long - play an essential role, as well. Insertions-deletions (InDels; smaller polymorphisms varying from one to 50-bp), inversion, translocation, and copy number variations $(\mathrm{CNV})$ all come under the umbrella of structural variations. Maize is the first cereal in which hundreds of SVs were identified. However, later, this number was found to be underestimated, and efforts were initiated to discover more SVs among higher eukaryotes [10].

The studies of structural variations were recently accelerated in the crop plants primarily due to the reference genome sequence generation. Based on the sequence similarity at the DNA breakpoints, SVs are formed mainly by two mechanisms, viz., non-homologous end-joining (NHEJ) and non-allelic homologous recombination (NAHR) [for review see 11]. Apart from these mechanisms, transposons also generate SV. In general, SVs can be detected mainly by three methods, viz., (1) re-sequencing, (2) the de novo assembly, and (3) the pan-genome assemblies. The resequencing approach mainly identifies CNV and presence-absence variations (PAV), whereas the de novo approach-along with CNV and PAV-also identifies inversions. Nevertheless, the resequencing approach remains the preferred approach to detect the SVs due to its low cost and lack of de novo assembly generation for each variety under investigation. The $\mathrm{CNVs}$ arise from the unbalanced DNA modifications that lead to the variable number of copies of a specific DNA sequence [10]. CNVs may vary from $1-\mathrm{kb}$ to several Mbs. Studies show that, along with SNPs and InDels, CNVs are key contributors to intra-species genetic variation. The PAVs can be considered as the extreme form of the CNVs. In PAV, a genomic sequence is present in one individual and absent from the other. In the past few years, SVs affect several traits in different cereals. For instance, 17.1-kb tandem duplication of GL7 locus in rice leads to an increase in the grain size [12], CNVs of $V r n-A 1$ and $P p d-B 1$ affects the flowering time in wheat [13], and a 7-bp deletion on HvGA20ox2 gene reduces the plant height and delay flowering time in barley [14]. 


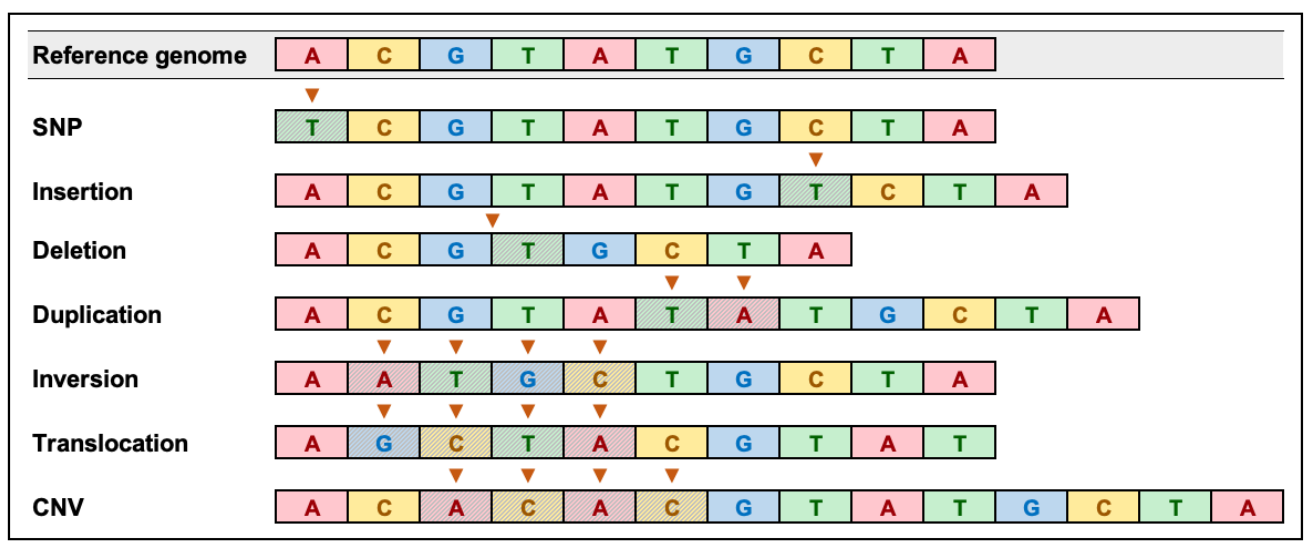

Figure 3. Types of structural variants. Inverted triangles show the position of a given variation with respect to the reference genome.

\subsection{Genetic mapping}

Several statistical methods can be employed to link the polymorphism to the traits under investigation - most common of which are regression analyses. In cereals - as for many other crops - polymorphisms or variations among individuals can be (1) artificially generated, i.e., via crossing different parents, and (2) surveyed in a natural population, e.g., set of elite lines, gene bank accessions, etc. In the following, we provide most common methods to link genetic polymorphisms to the traits under investigation.

\subsubsection{Linkage mapping}

Linkage mapping refers to mapping the quantitative trait loci (QTLs) in mostly artificially created segregating population/s. Many traits of economic importance, such as grain yield, stress tolerance, and disease resistance, are of quantitative nature, i.e., they are governed by a concerted action of many genetic loci [2]. Therefore, segregating populations harboring virtually hundreds of individuals are required to dissect the genetic nature of a quantitative trait. Different types of segregating populations such as F2 population, recombinant inbred lines (RILs), doubled haploid (DH) population, heterogeneous inbred family (HIF), near-isogenic lines (NIL), advanced intercross recombinant inbred lines (AI-RIL), backcross inbred lines, and multiparent advanced generation intercross (MAGIC) are developed based mainly on the available resources and research objectives. These segregating populations are mostly based on crosses between contrasting parents, resulting in a limited genetic diversity. Linkage mapping is the most commonly used method to detect genes underlying essential traits. Nevertheless, resources and time to develop these mapping populations coupled with a narrow genetic base plus low allelic richness and mapping resolution are some of the drawbacks of linkage mapping.

\subsubsection{Genome-wide association studies}

Genome-wide association studies (GWAS) take advantage of the long history of recombination events in the diverse natural population to dissect the genetic nature of a trait. The use of natural population overcomes the constraints of the linkage mapping as it increases the mapping resolution and reduces the research time [15] GWAS was initially used to study the human's complex traits, and then it was adopted for animals and some model organisms. In the last decade, with the improvements in genotyping techniques, decreased cost of sequencing, and robust statistical methods, researchers have adopted the GWAS for dissecting the genetic architecture of complex traits in plants. GWAS identifies marker-trait associations (MTA) that can be attributed to the strength of linkage disequilibrium (LD) between polymorphic markers across a set of diverse germplasm. In a nutshell, GWAS analysis is performed to evaluate each genotyped marker's association with a trait of interest that has been scored across a diverse natural population. GWAS analysis can be used to study both qualitative and quantitative traits. Several aspects must 
be considered for starting the research, e.g., selection of genotyping platform, sample or population size and structure, statistical analyses, and correction for multiple testing (Bonferroni correction, false discovery rate (FDR) correction factor). Table 1 describes the use of linkage mapping, GWAS, or both for cereal improvement.

Table 1. List of five major cereals and the major traits studied via linkage mapping (LM) and genome-wide association studies (GWAS).

\begin{tabular}{|c|c|c|c|}
\hline $\begin{array}{l}\text { Crop } \\
\text { name }\end{array}$ & $\begin{array}{l}\text { Mapping } \\
\text { method }\end{array}$ & $\begin{array}{c}\text { Trait or } \\
\text { gene studied }\end{array}$ & Reference \\
\hline Rice & LM and GWAS & Seed vigor & [16] \\
\hline Rice & LM and GWAS & Bacterial blight resistant gene, $\mathrm{Xa43}(t)$ & [17] \\
\hline Rice & LM and GWAS & Grain shape and grain weight & [18] \\
\hline Rice & GWAS & Plant architecture & [19] \\
\hline Rice & GWAS & Salt tolerance, OsSTL1 and OsSTL2 & [20] \\
\hline Wheat & LM & Plant height and yield & [21] \\
\hline Wheat & LM & Grain shape and size & [22] \\
\hline Wheat & LM & Reduced plant height gene, $R h t 24$ & [23] \\
\hline Wheat & GWAS & $\begin{array}{l}\text { Floret fertility, assimilate partitioning } \\
\text { and spike morphology traits }\end{array}$ & [24] \\
\hline Wheat & GWAS & Total spikelet number & [25] \\
\hline Maize & LM & Resistance to northern leaf blight & [26] \\
\hline Maize & LM and GWAS & Plant and ear height & [27] \\
\hline Maize & LM and GWAS & Male inflorescence size & [28] \\
\hline Maize & GWAS & Lipid biosynthesis & [29] \\
\hline Maize & GWAS & Root morphology traits & [30] \\
\hline Barley & LM & Plant height & [31] \\
\hline Barley & LM & Awn length & [32] \\
\hline Barley & GWAS & Photoperiod response & [33] \\
\hline Barley & GWAS & Nitrogen use efficiency & [34] \\
\hline Barley & GWAS & Spikelet number and grain yield & [35] \\
\hline Sorghum & LM & $\begin{array}{l}\text { Plant height, node number, panicle length, } \\
\text { flag leaf length, and flag leaf width }\end{array}$ & [36] \\
\hline Sorghum & LM and GWAS & Grain quality traits & [37] \\
\hline Sorghum & GWAS & $\begin{array}{l}\text { Plant architecture traits (e.g., tiller number, } \\
\text { panicle length, seed number, internode length) }\end{array}$ & [38] \\
\hline Sorghum & GWAS & Kernel composition & [39] \\
\hline Sorghum & GWAS & Grain size & [40] \\
\hline
\end{tabular}

\subsection{The study of species-level variations via pangenomes}

The pangenome aims to catalog genic presence-absence variations within a species [41]. A pangenome contains a core genome, i.e., genomic sequences present in all the individuals of a species - and a variable genome, i.e., genomic sequences present in some individuals. The first step to establish a pangenome in any crop species is selecting a diverse set of genotypes, including domesticated and wild progenitors, for sequence assembly. It is also wise to choose genotypes of breeding and genetic value to increase the pangenome's importance for future breeding programs. Genotypes belonging to secondary and tertiary gene pools of a particular species are added to form a genus-level pan-genome. The reference-quality genomes are then generated for the small set of accessions 
and aligned to the reference genome to detect the structural variations. $\mathrm{k}$-mers present in the SVs are extracted and determined in the form of short-read data from a diversity panel to genotype the underlying SV, and the matrices of the k-mers count are used as biallelic markers in the QTL mapping or genome-wide association studies [42]. Pangenome has already been established in various cereals, viz, rice [43], wheat [44], and barley [41]. In barley, a pangenome of 20 barley assemblies was constructed, single-copy k-mers from the structural variants in these 20 assemblies were detected, and a k-mer abundance matrix was used to perform the GWAS for lemma adherence [41].

\subsection{Challenges and prospects in crop-genomics}

In the past, whole-genome sequencing efforts were hindered mainly by the (1) extensive and repetitive genome sequences of the cereals and (2) the absence of current technologies and algorithms that are robust and exact in generating and assembling the large and correct sequences. Therefore, this has been perhaps the most important reason why considerable international consortia efforts were required. Although large-scale genome sequence production and assembling are currently costly, with continuous innovation in technologies, future large-scale reference-quality genome assemblies will be easier mainly because of the small cost-outcome differential. It can be safely speculated that the construction of genome assemblies will continue to the point where the difference between whole-genome genotyping and whole-genome sequencing will be negligible [4]. With the improvements in sequencing and computing facilities, the production per unit of input will be improved, which will be beneficial for cereal geneticists and breeders. As described elsewhere, robust QTL mapping and gene cloning hinge on dense genetic/physical maps' availability. Advances in genomics will help in fast and accurate mapping of the traits. Also, with the availability of the dense marker information, the methods of prediction of genotypic (in case of inbreeding crops) or breeding (additive) value (in case of outcrosses) will become more efficient to improve the genetic gains per unit time and cost.

\section{Cereal transcriptomics}

The genetic content in all the cells of an organism is the same; even then, different cells perform different functions and possess varying compositions under diverse circumstances. As per the central dogma of molecular biology, DNA is transcribed to RNA, and further RNA is translated to proteins, which are functional units [45]. Therefore, mRNA serves as transient molecules in the execution of genetic information stored in DNA. The whole set of RNA transcripts produced by an organism under any specific conditions is called transcriptome, and the study of this transcriptome is known as transcriptomics [46].

\subsection{Transcriptomics techniques}

The first attempt to study RNA transcripts was made in the 1970s when mRNA libraries of silk moths were converted to cDNA using reverse transcriptase [47]. Later in the 1980s, Sanger sequencing was used to sequence the RNA transcripts, called Expressed Sequence Tags (ESTs) [46]. EST was used as a technique to determine the gene content of an organism. Later, RNA transcript quantification was also performed using various techniques such as northern blotting and then by qRT-PCR [48]. However, these techniques do not cover the entire transcriptome, but only a small part of it. In 1995, the first method developed and used for transcriptomics was sequencing-based called Serial Analysis of Gene Expression (SAGE) [49].

SAGE methodology involved preparing a short sequence tag (10-14 bp) from each transcript's unique positions, which can be used to identify a transcript. Sequence tags are then linked together to form long serial molecules. These molecules are then cloned and sequenced. To check the expression of a specific gene, a total number of tags are counted. Quantification of the number of times a particular tag provides the expression level of the corresponding gene. SAGE can also help to identify new genes expressing in a tissue or under specific conditions [49]. 
Massively parallel signature sequencing (MPSS) is a sequencing-based approach used to analyze a level of gene expression by quantifying mRNA transcripts present in the samples. MPSS uses a 17-20 bp signature sequence adjacent to the $3^{\prime}$-end of mRNA to identify mRNA. Each signature sequence is first cloned on to microbeads. This technique ensures that only one type of DNA sequence is on a microbead. The microbeads are arrayed in a flow cell for sequencing and quantification. Each signature sequence (MPSS tag) in a MPSS dataset is analyzed, compared with all other signatures, and all identical signatures are counted. The expression level of any single gene is calculated by dividing the total number of signatures for that gene present in the samples with all signature sequences identified.

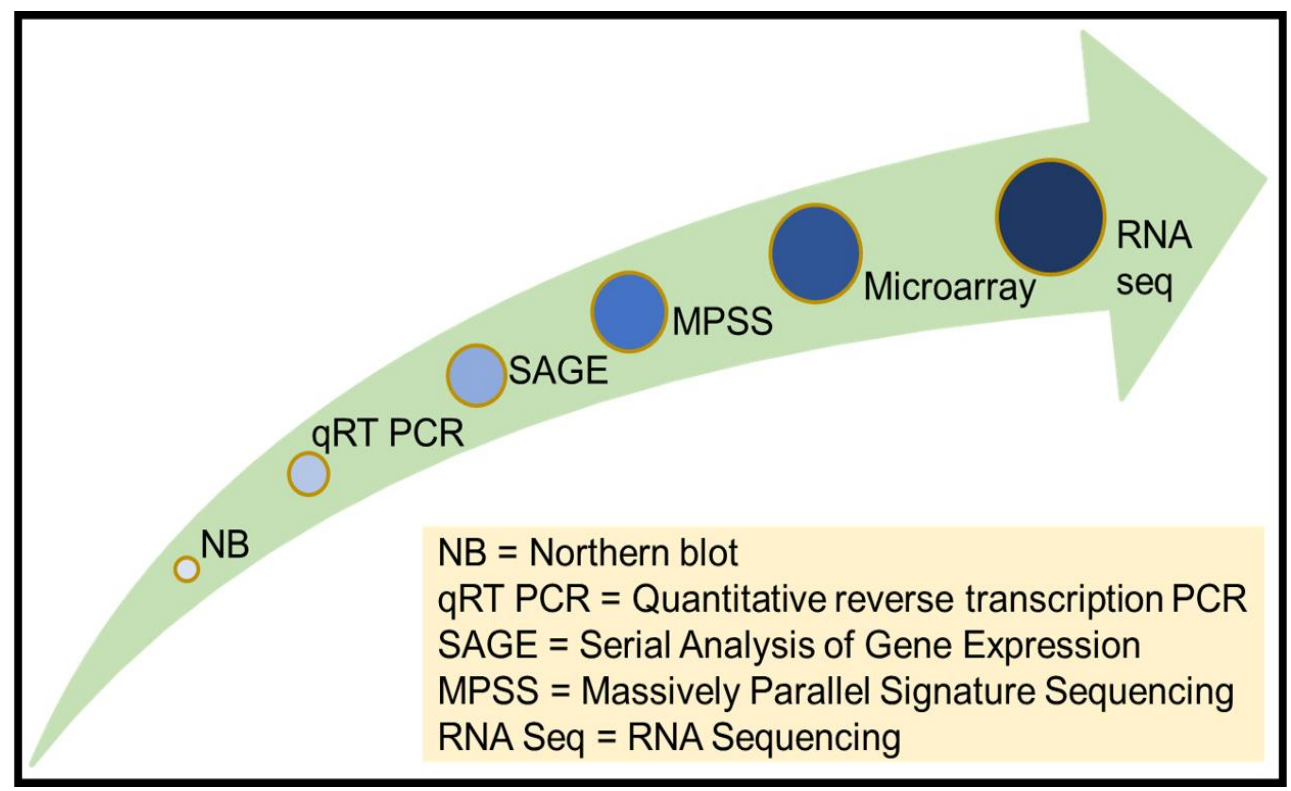

Figure 4. Development in techniques of gene expression analysis from few targeted genes to whole-genome transcriptome.

Later, two well-defined techniques that provided high throughput transcriptomics data came into existence: Microarray and RNA-Seq. The progression and advancements in techniques of gene expression analysis are displayed in figure 4 . Microarray quantifies a set of the RNA transcripts by their hybridization to complementary probes fixed on a platform. It was used to assay thousands of genes with a low cost per unit gene. Advancements in designing arrays and fluorescence detection systems have boosted the sensitivity and accuracy of this technique. A microarray consists of several probes on a solid platform, i.e., a glass or a silicon chip. The fluorescent-labeled transcripts then hybridize on these chips to complement the probes. The amount or intensity of fluorescence at each probe quantifies the respective transcript [50]. Microarrays are broadly of two categories: - low-density spotted array and high-density probe array. Low-density spotted arrays use large probes and various fluorophores for test and control, whereas high-density probes arrays have higher resolution and use a single fluorophore for the test [51]. Initially, Affymetrix (Santa Clara, CA) Gene chip array developed a high-density array, and later, Nimble Gen developed a more advanced high-density array by mask-less photochemistry. Even though this technique is efficient in revealing the transcripts in an organism, it requires prior knowledge of ESTs and an organism's genome assembly so that probes could be designed to generate the chip.

RNA-seq is defined as sequencing cDNAs of mRNA transcripts and quantifying them based on the number of each transcript. High-throughput sequencing platforms have highly reduced the cost of sequencing and increase the level of accuracy. New sequencing platforms such as Roche 454, Illumina, SOLiD, Pac Bio, and Nanopore (com- 
pared in Table 2) have aided the RNA seq technique to provide extensive genome coverage $[52,53]$. RNA seq provides a tremendous amount of information about the genes present \& activation of these genes at a particular time point under specific conditions. In recent years, the availability of NGS sequencing technologies has boosted RNA-seq over microarray technique, illustrated by google trends of the last ten years (Figure 5).

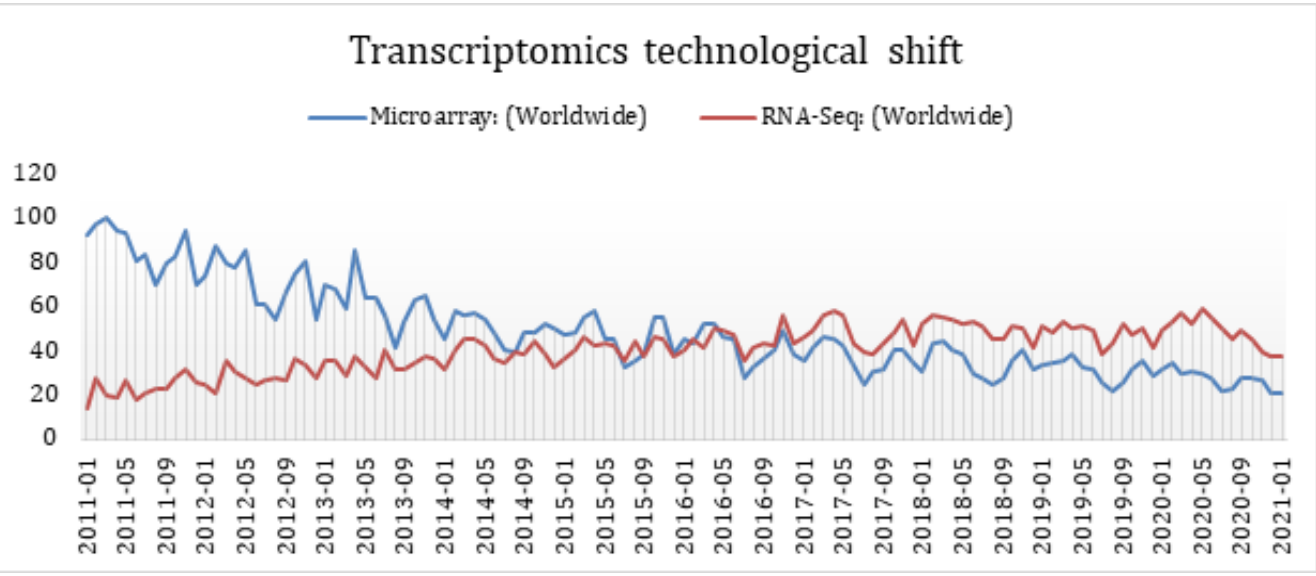

Figure 5. The popularity of Google search "Microarray" and "RNA-Seq" for the last ten years depicts the technological shift in transcriptomics. (Source: Google Trends).

Only the mRNA transcripts are sorted out from different kinds of RNAs for RNAsequencing. The mRNA with $5^{\prime}$-cap and poly-A tail are separated by poly-A tail specific probes. Small RNAs are removed based on their size by using gel electrophoresis. The mRNAs are fragmented as per the read length limit of the sequencing technology through hydrolysis or sonication. The selected mRNA is used to synthesize cDNA, which could be amplified if the amount is not sufficient and finally used as reads for sequencing through NGS platforms [54]. Presently, Nanopore technology is used for RNA-seq, which directly sequences RNA without conversion into cDNA. It is better than previous sequencing techniques as it detects the modified bases, which were otherwise masked during cDNA synthesis, and prevents the biasness introduced during the cDNA amplification step. The number of reads and amount of coverage of the genome determines the sensitivity and accuracy of RNA seq. The Encyclopedia of DNA Elements (ENCODES) recommends 70x coverage for standard RNA seq and even 500x coverage for rare transcripts [55].

Table 2. Comparison of Next Generation Sequencing platforms used for RNA Sequencing.

\begin{tabular}{|c|c|c|c|c|c|}
\hline Platform & $\begin{array}{l}\text { Read } \\
\text { length }\end{array}$ & Chemistry & $\begin{array}{c}\text { Amplification } \\
\text { method }\end{array}$ & $\begin{array}{c}\text { Read } \\
\text { pair }\end{array}$ & $\begin{array}{l}\text { Overall } \\
\text { error rate }\end{array}$ \\
\hline Sanger sequencing & 750-bp & Chain termination & PCR & Yes & - \\
\hline 454 Roche & 700-bp & Pyrosequencing & Emulsion PCR & Yes & $0.5 \%$ \\
\hline HiSeq Ilumina & 50-250-bp & Reversible terminator & Solid-phase PCR & Yes & $0.2 \%$ \\
\hline SOLiD & $50-b p$ & Sequencing by ligation & Emulsion PCR & Yes & $0.1 \%$ \\
\hline Ion torrent & 100-400-bp & Proton detection & Emulsion PCR & Yes & $1 \%$ \\
\hline Pac bio & $14-\mathrm{kb}$ & Real-time sequencing & $\begin{array}{l}\text { Real-time single- } \\
\text { molecular template }\end{array}$ & No & $15 \%$ \\
\hline Nanopore & $10-\mathrm{kb}$ & $\begin{array}{l}\text { Disruption of ionic current } \\
\text { flow through nanopores }\end{array}$ & Not required & No & $10-40 \%$ \\
\hline
\end{tabular}

\subsection{Transcriptome for improving abiotic stress tolerance in plants}

With an increase in the whole genome transcriptomic studies in plants, the genes related to stress response, downstream signaling, and synthesis of stress response molecules are undermined [56]. A plethora of information on transcriptomics of cereals crops 
such as rice, wheat, maize, barley, and sorghum are available. This information has provided insight into the coordination of different biological processes in various plant tissues under stress conditions [57]. The study of drought stress during the flowering or fruiting stage of the plant gives information about the reproductive system's interaction, hormone signaling, and metabolic pathways. Table 3 highlights the use of microarray and RNA-seq techniques in different crops to identify differentially regulated genes during various abiotic stress conditions.

The comparative transcriptome analysis between drought-tolerant and susceptible cultivars indicates candidate genes and the mechanism of adaptations under drought stress [58]. Earlier studies revealed that 20 CIPK genes are upregulated in rice, specifically under drought stress conditions. However, recent RNA seq experiments state that the overexpression of CIPK genes under various abiotic stresses such as salinity stress, cold stress, and ABA treatment [59]. RNA seq studies reported that rice cultivars tolerant to salinity have a quick response to salinity, earlier induction of $\mathrm{H}_{2} \mathrm{O}_{2}$, and signal transduction compared to sensitive ones [60]. Salinity tolerant cultivars set up an adaptive program by limiting sodium to roots and old leaves of the plants and activating the genes related to photosynthesis in new leaves. Two inbred lines with extreme cold tolerance and sensitivity were used for whole-genome transcriptomics and bioinformatic analysis of transcriptomic data reported that 948 DEGs out of a total of 19,794 genes were mainly responsible for DNA binding, ATP binding, and protein kinase [61]. RNA seq of drought-resistant and drought-susceptible cultivars of sorghum at seedling stage under PEG-induced drought revealed 180 differentially expressed genes, and 70 genes upregulated in response to drought stress were uncharacterized novel genes or associated with transcription factors and signal transduction under stress [62].

Table 3. Application of transcriptomics for improving field crops against abiotic stresses.

\begin{tabular}{ccccc}
\hline $\begin{array}{c}\text { Crop } \\
\text { name }\end{array}$ & Tissue & Technique & Abiotic stress & Reference \\
\hline Rice & Leaves & RNA Seq & Drought & {$[63]$} \\
Rice & Leaves & Microarray & Cold & {$[64]$} \\
Rice & Leaves and shoot & RNA Seq & Adaptive and salinity & {$[60]$} \\
\hline Wheat & Roots & RNA Seq & Drought & {$[65]$} \\
Wheat & Crown tissue and leaves & RNA Seq & Cold and light & {$[66]$} \\
Wheat & Shoots and roots & Microarray & Salinity & {$[67]$} \\
\hline Maize & Tassels & RNA Seq & Drought & {$[68]$} \\
Maize & Leaves & RNA Seq & Salinity & {$[69]$} \\
Maize & Leaves & RNA Seq & Cold & {$[61]$} \\
\hline Barley & Leaves and roots & Microarray & Drought & {$[70]$} \\
Barley & Roots & RNA Seq & Salinity & {$[71]$} \\
\hline Sorghum & Seedlings & RNA Seq & Drought & {$[62]$} \\
Sorghum & Seedlings & RNA Seq & Salinity & {$[72]$} \\
Sorghum & Seedlings & RNA Seq & Salinity & {$[73]$} \\
\hline
\end{tabular}

\subsection{Transcriptomics for crop improvement against biotic stress}

Crop yield is challenged by various biotic stresses such as bacteria, viruses, fungi, insect-pest, and weeds [74]. Most of the plant breeding programs target developing the genotypes, which are tolerant or resistant to plant pathogens and insect-pests so that crop loss due to biotic stress could be mitigated. Plants have evolved with various biochemical and physiological mechanisms to escape biotic stresses [75]. In response to pathogens infection, plants activate salicylic acid (SA), jasmonic acid (JA) and ethylene (ET) signaling, reactive oxygen species (ROS) production, hypersensitive response, the release of toxic compounds, and phytoalexins [76]. Therefore, understanding the molecular level changes 
in plants in response to pathogen attack is crucial to develop disease-resistant crop varieties.

Various transcriptomic studies are conducted in cereal crops to decipher the disease resistance mechanisms and to identify resistance $(R)$-genes. The whole-genome transcriptome analysis of four wheat cultivars Wuhan 1, Nyubai, HC374, and Shaw, after head inoculation with Fusarium graminearum, revealed upregulation of leucine-rich repeats receptor kinases (LRR-RKs), a class of receptor kinases involved in disease resistance during different time points resistant and susceptible cultivars and differential expression profile of different genotypes shows various genotype-specific defense responses [77]. Table 4 summarizes other important examples where transcriptome data was used to study the plant response against various plant pathogens. Mangnaporthe oryzae causing blast disease in rice was the first pathogenic fungus to be sequenced. Hence Magnaporthe oryzaerice is considered as a model pathosystem to understand molecular host-pathogen interactions. High-quality transcriptomic studies via RNA seq provide essential information to dig out genomic level interactions of host-pathogen systems [78]. It is well known that the Xa23 gene in Oryza sativa confers broad-spectrum resistance to most of the biotypes of Xanthomonas oryzae pv. oryzae (Xoo). The transcriptome profiling of NILs with Xa23 (CBB23) and without Xa23 (JG30) before and after inoculation with Xoo provides insight into the downstream genes and pathways involved in the resistance provided by the Xa23 gene. In total, 1645 DEGs were found, and most of these are associated with phenylpropanoid biosynthesis, followed by flavonoid biosynthesis and phytohormone signaling [79].

Table 4. Improvement field crops against biotic stresses using RNA sequencing.

\begin{tabular}{cccc}
\hline $\begin{array}{c}\text { Crop } \\
\text { name }\end{array}$ & Tissue & Biotic stress & Reference \\
\hline Rice & Leaves & Magnaporthe oryzae & {$[78]$} \\
Rice & Leaves & Xanthomonas oryzae pv. oryzae & {$[79]$} \\
Rice & Leaf sheath & Rhizoctonia solani & {$[80]$} \\
\hline Wheat & Spikes & Fusarium graminearum & {$[77]$} \\
Wheat & Seedlings & Puccinia triticina & {$[81]$} \\
Wheat & Leaves & Puccinia striiformis f. sp. tritici & {$[82]$} \\
\hline Maize & Leaves & Cercospora zeae-maydis; Cercospora zeina & {$[83]$} \\
Maize & Leaves & Fusarium graminearum & {$[84]$} \\
Maize & Leaves & Maize Iranian mosaic virus & {$[85]$} \\
\hline Barley & Leaves & Ramularia coolo-cygni & {$[86]$} \\
Barley & Leaves & Blumeria graminis f. sp. hordei & {$[87]$} \\
Barley & Leaves & Rhynchosporium secalis; Cochliobolus sativus & {$[88]$} \\
\hline
\end{tabular}

\subsection{Challenges and prospects in transcriptomics}

Transcriptomic studies had various challenges from time to time, most of these are resolved with the advancement of techniques, and some are still in the pipeline. Microarray is limited to depict the expression level of only known genes. This was sorted out by RNA-seq, which provides the complete profile of the transcript present at the stage or time of an organism without missing any transcript. It lowers the background and increases the experiment's clarity, whereas analysis of NGS data in RNA-seq is tedious and time-consuming. NGS procedures have hurdles that read coverage may not be uniform along the genome due to variation in nucleotide composition between genomic regions. In RNA-seq, a long transcript is estimated to have more reads than a short transcript at the same expression level. To normalize the counts with respect to transcript length, some software packages are used that represent RNA-seq data by transformed quantities such as RPKM (Reads Per Kilobase per Million mapped reads) or the related FPKM (Fragments 
Per Kilobase per Million mapped reads). The software, such as Cufflinks/Cuffdiff, provides an integrated analysis pipeline from the aligned reads to the differential expression results, where the inference is based on FPKM values. Further improvements in RNA-seq are revolutionizing the transcriptomics studies in plants to develop crop varieties in the near future which can withstand biotic and abiotic stress and produce a higher yield.

\section{Cereal proteomics}

The advances in genomic techniques provide a blueprint of possible gene products that have changed our way of studying biological systems. As the genome is static, it lacks to provide the correlation between mRNA and protein abundance due to post-translational modifications, protein function, and localization. Also, it does not give the biological snapshot of an organism at a particular developmental time point. Therefore, it is essential to study the protein structure, their interactions to explore their role during plant growth and development. Proteomics is a systemic, high-throughput approach for comprehensive identification and analysis of protein expression in a cell, tissue, or organelle of an organism at a particular time under specific conditions [89]. The very first report of 2-DE dates back to 1975, which provided the first glimpse of the protein levels and the isoforms of the cells. Marc Wilkins coined the term proteomics in 1994 as the extension of the word "proteome" (PROTein complement of the genOME) at the first 2-DE meeting in Siena, Italy [90]. The study of proteome profiles provides deep insight into various metabolic processes and their interaction with different regulatory pathways in a biological system. Proteomics is a powerful tool providing robust and better representation of the cell functioning than other techniques, including genomics tools.

The advancements in proteomics in the last decade have led to new and improved technologies, including two-dimensional polyacrylamide gel electrophoresis (2D-PAGE), liquid chromatography (LC), mass spectrometry (MS), etc. which have enabled fast and accurate protein identifications.

\subsection{Technical advances in proteomics}

In the recent past, various proteomics approaches have been developed and adopted in plants. These tools pave the way for high-throughput proteome analysis for quantification, localization, protein-protein interactions, and post-translational modifications (PTMs). All proteomics technologies have three main steps, including protein extraction, separation (gel-based or gel-free/Column-based methods), and identification or quantification (Mass Spectrometry, MS) [91]. The Gel-free techniques can be label-free such as liquid chromatography coupled with mass spectrometry, LC-MS or tag-based such as ICAT, iTRAQ, etc. [92] (Figure 6). A single technology cannot comprehensively analyze complete plant proteome due to its complex and dynamic nature. Therefore, multiple approaches are used to improve the understanding, resolution, and coverage of plant proteome. Table 5 provides knowledge about different proteomics techniques used to study abiotic and biotic stress responses in cereal crops, including wheat, barley, rice, maize, and sorghum. Various factors such as availability of resources, facilities, and applications like global or targeted profiling decide the proteome's approaches [91]. 


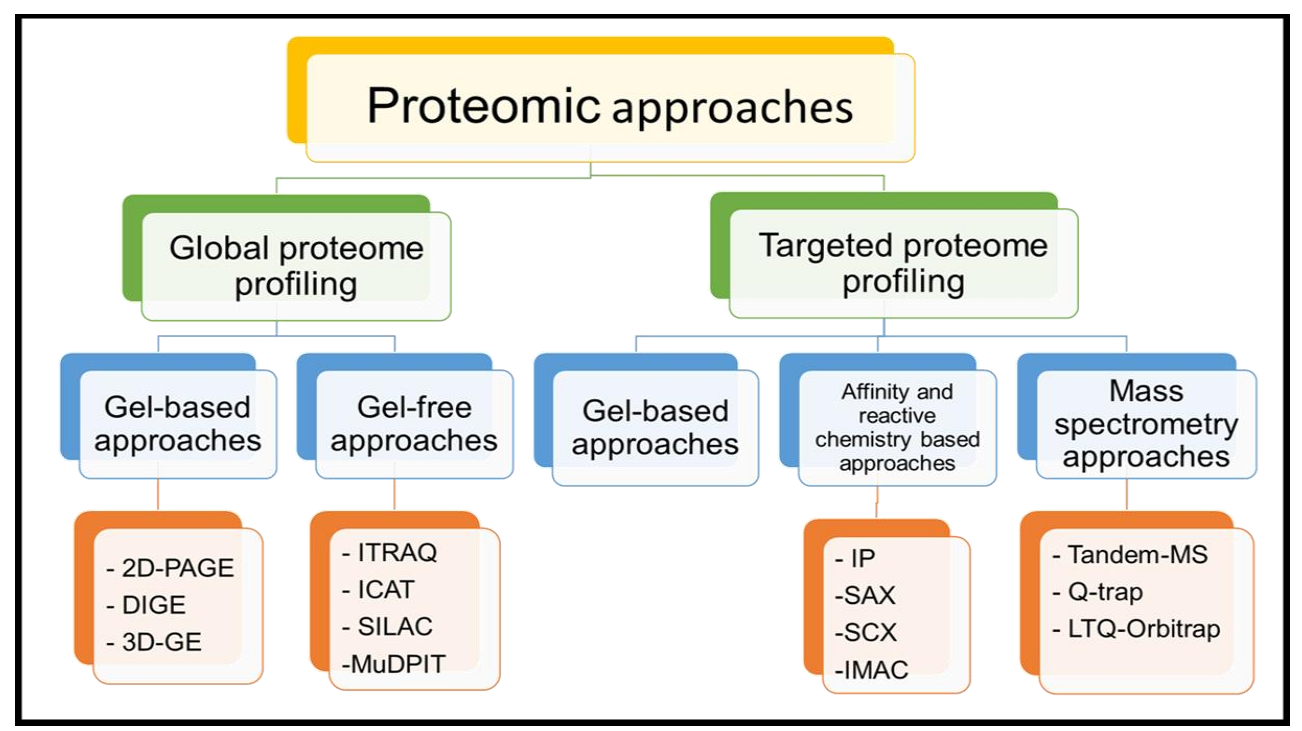

Figure 6. Schematic representation of various proteomics approaches.

\subsection{Global proteome profiling}

It is considered one of the best approaches for comparing two or more proteomes or generating a reference proteome map. It is categorized into gel-based and gel-free/shotgun approaches [93]. The gel-free proteomics is gaining popularity with the passing years due to increased reproducibility and less bias than gel-based proteomics [94].

\subsubsection{Gel-based approaches}

These are the most popular, versatile and mature methods of protein separation and quantification. They allow the identification of low-abundance proteins and characterization of protein isoforms on a large scale and are less expensive than gel-free approaches.

Two-dimensional polyacrylamide gel electrophoresis (2D-PAGE) is considered the workhorse of proteomics due to its affordability and acquaintance. It resolves proteins based on two independent parameters: isoelectric point (pI) and molecular mass (M). The resolved proteins can be stained with Coomassie blue, silver nitrate, or SYPRO Ruby for their visualization. It is widely used in expression proteomics studies.

Difference in gel electrophoresis (DIGE) has been developed to overcome the gel-togel variation and less reproducibility of 2D-PAGE. In this approach, many protein samples labeled at their lysine residues by different fluorophores (CyDye2, CyDye3, CyDye5) are simultaneously separated on a single gel [95]. DIGE is used to elucidate variations in protein expression in response to various biotic and abiotic stresses.

Three-dimensional gel electrophoresis (3DGE) is an advancement of 2D-PAGE to overcome the co-migration interferences [96]. It uses two different buffers with different ion carriers and gives very accurate protein and post-translational modifications (PTMs) identification [97].

\subsubsection{Gel-free approaches}

Gel-free approaches are developed to overcome the limitations of gel-based approaches, such as the inability to separate the entire proteome, rare detection of low abundance proteins, and labor-intensive. These include quantitative approaches like tag-based labeling (ICAT, iTRAQ), metabolic labeling (SILAC), and label-free methods (MudPIT) [93]. 
Isotope-Coded Affinity Tagging (ICAT) is an in-vitro isotopic labeling approach for protein quantification, which involves the use of an affinity tag (biotin), linker having stable isotope, and a reactive group that binds to thiol groups (cysteines) of proteins. The labeled tryptic peptides are first fractionated by chromatography and then identified by mass spectrometry (MS) [98]. ICAT mainly contributes to identify novel proteins controlling a vital biological function in a particular cultivar [99].

Isobaric Tagging for Relative and Absolute Quantification (iTRAQ) is a multiplex protein quantification technique utilizing the isobaric tags for labeling the $\mathrm{N}$-terminus and side-chain amine groups of proteins. The sensitivity of protein quantification from different sources in one test is much higher than ICAT [100]. Crop breeders use this technique to elucidate markers for biotic and abiotic stresses, and those later can be used in designing genetically modified crops.

Stable Isotope Labelling by Amino Acid in Cell Culture (SILAC) is a metabolic labeling technique that is the most potent approach for dynamic quantitative plant proteome studies. It utilizes in-vivo labeling of cell population grown in either N14 or N15 containing medium [101]. It is advantageous to identify proteome changes in signaling pathways triggered by PTMs in response to stress [102].

Multi-dimensional protein identification technology (MudPIT) is a shotgun proteomics tool used for complex multi-dimensional protein analysis [94]. It is a less complex and highly sensitive technique for the identification of low abundance proteins. In this approach, the biphasic or triphasic microcapillary columns are used to separate digested proteins, followed by performing tandem MS. This technology has been used to unravel the mechanisms involved in controlling tiller numbers in rice.

\subsection{Targeted proteome profiling}

It is a selective proteome analysis of interacting proteins or post-transcriptionally modified proteins using PTM-specific stains, antibodies, or targeted MS assays [91]. It can be classified into gel-based, affinity and reactive chemistry-based and MS-based targeted proteomics.

\subsubsection{Gel-based proteomics}

The global proteome analysis is undertaken using 2D-PAGE, followed by staining with Phosphoprotein specific gel stain (Pro-Q Diamond) (PTM specific stain). However, these approaches are not used these days due to a lack of identification of less abundant proteins [91].

\subsubsection{Affinity and Reactive chemistry-based proteomics}

In this approach, specific proteins are isolated, enriched, and purified by different techniques such as immunoprecipitation (IP), strong cation exchange (SCX), strong anion exchange (SAX), and immobilized metal affinity chromatography (IMAC). These techniques can be used individually or coupled with one another to enhance efficiency.

\subsubsection{MS-based proteomics}

They are based on detecting signals resulting from transitions in the ions during the fragmentation in the mass spectrometer. Various tools like tandem MS, Quadrupole trap (Qtrap), triple quadrupole, and Linear Trap Quadrupole Orbitrap (LTQ- Orbitrap) are commonly used. Selected Reaction Monitoring (SRM) is the process of detection of transitions in triple quadrupole, whereas Multiple Reaction Monitoring (MRM) is the detection of multiple modifications [103]. However, the afore-mentioned techniques suffer from precision errors between samples. To overcome this shortcoming, SRM/MRM techniques are isotopically labeled [104]. 
Table 5. Application of various proteomics technologies for improving field crops against abiotic and biotic stresses during the last decade.

\begin{tabular}{cccc}
\hline $\begin{array}{c}\text { Crop } \\
\text { name }\end{array}$ & Abiotic/ & Techniques & References \\
\hline Rice & Drotic stresses & LC-MS/MS & {$[105]$} \\
Rice & Response to selenium & 2DE & {$[106]$} \\
Rice & Bakanae disease & TMT-MS & {$[107]$} \\
Rice & Bacterial blight & 2DE/MudPIT, MALDI-TOF/MS & {$[108]$} \\
\hline Wheat & Drought & 2D-PAGE & {$[109]$} \\
Wheat & Drought & 2DE, MALDI-TOF-TOF-MS & {$[110]$} \\
Wheat & Yellow rust & nanoLC ESI-MS/MS & {$[111]$} \\
Wheat & Yellow rust & 2D-PAGE & {$[112]$} \\
\hline Maize & Salinity & iTRAQ, LC-MS/MS & {$[113]$} \\
Maize & Heavy metal & iTRAQ, LC-MS/MS & {$[114]$} \\
Maize & Ear rot disease & iTRAQ & {$[115]$} \\
Maize & Maize rough dwarf disease & LC-MS/MS, TMT labeling & {$[116]$} \\
\hline Barley & Drought & DIGE \& LTQ-Orbitrap & {$[117]$} \\
Barley & Salinity & 2D-PAGE & {$[118]$} \\
Barley & Leaf rust & LC-MS/MS & {$[119]$} \\
Barley & Fusarium head blight & 2D-PAGE, MS & {$[120]$} \\
Barley & Powdery mildew & LC-MS & {$[121]$} \\
\hline Sorghum & Heavy metal toxicity & 2D-PAGE & {$[122]$} \\
Sorghum & Drought & DIGE & {$[123]$} \\
Sorghum & Downy mildew & 2D-PAGE, MLADI-TOF/MS & {$[124]$} \\
\hline
\end{tabular}

\subsection{Bioinformatics in Proteomics}

The technical advances in proteomics approaches have made it possible to achieve a massive amount of high-quality protein expression data. It is challenging to associate this data with other-omics technologies like genomics, transcriptomics, metabolomics, and phenomics. Bioinformatics plays a fundamental role in overcoming this bottleneck by reducing the analysis time and providing statistically significant results. Some of the major proteomics databases currently used are PRoteomics IDEntification database (PRIDE) [125], Peptide Atlas [126], and Mass Spectrometry Interactive Virtual Environment (MassIVE). Various comprehensive databases for plant proteomics such as Plant Proteomics Database (PPDB), 1001 Proteomes, Pep2 Pro Database, DIPOS, etc. [127-130] as well as different web-based prediction tools like GelMap [131], MRMaid [132], Peptide Atlas SRM Experiment Library (PASSEL) [133], etc. have been developed to assist proteome analysis.

\subsection{Challenges and prospects in proteomics}

The proteomic analysis complements both transcriptomics and metabolomics for elucidating plants' cellular mechanism and, thus, is a vital tool for crop improvement. The recent advancements in proteomics techniques have enabled us to unravel plant biology. However, we still need to overcome the various limitations of these techniques to develop smart crops with high grain quality and capable of withstanding multiple stresses. New emerging technologies such as peptidome, phosphoproteomics, and redox proteomics will provide in-depth insight into molecular interactions and protein function [134]. With the ever-changing climate, new plant variants are being introduced continuously to cope with these fluctuations. Novel proteomic tools will enable us to generate more stress-tolerant or stress-adaptive cultivars.

\section{Cereal metabolomics}


Metabolomics is a relatively new "-omics" technology for deciphering the plant metabolomes and, hence understanding the complex biological systems. Metabolomics allows a comprehensive profiling and comparison of a small molecules $(<1500 \mathrm{Da})$ of a cell, tissue, organ, or organism [135]. Metabolomics deals with the identification and quantification of metabolites in a biological system for investigating their compositions and interactions with environment [136]. Moreover, compared with genomics, transcriptomics, and proteomics, metabolomics focuses on investigating the biological activities, and, therefore, is relatively easier to relate to the phenotype [137].

Based on the purpose of the study, metabolomics can be differentiated into two types, viz., targeted and untargeted. Targeted metabolomics deals with the absolute quantification of one or a few metabolites in a set of predefined known substances. The targeted approach, therefore, tends to be highly sensitive and quantitative, and can be useful to trail the metabolites known to be associated with specific stress. Thus, targeted metabolomics is a discovery-based approach and measures the relative abundances of several hundred to thousands of all detectable metabolites. The Untargeted approach, on the other hand, can measure mass spectrometric features of unknown metabolites, and thus enhances the chances of sensing unintended effects [136].

In recent years, metabolomics has been used to understand biotic and abiotic stresses in crop plants, and many studies summarize the metabolomic advances in corn, sorghum, wheat, rice, and barley, investigating the composition of these crops and/or their products and their applications for crop improvement (reviewed in [138-140]). Understanding the plant metabolomic processes would be beneficial for improving crop yield and human nutrition aspects in crop breeding programs Future perspectives of metabolomics integrating other "-omics" technologies were also highlighted.

\subsection{Overview of metabolomic pipeline}

The workflow for metabolomics involves a series of steps, including experimental design, sample preparation and extraction, metabolite detection using analytical techniques, and data processing and analysis using bioinformatics techniques. Since metabolomics involves a wide range of diverse compounds, variations in metabolite concentration ( 106) can complicate the downstream analyses [137]. Thus, it is essential to carefully choose (1) the appropriate experimental design, (2) optimize sample preparation and extraction protocols, and (3) detection technologies for comprehensive metabolomic analyses.

Numerous extraction protocols are available for metabolomics analysis [141,142]. Standard sample preparation protocols involve plant material collection in liquid nitrogen followed by rapid cooling or freeze-drying of sample and then extraction using $80 \%$ or $100 \%$ methanol [143]. Furthermore, experimental parameters such as the concentration of solvents, extraction time, and temperature can also influence the observed metabolite profiles. Hence, optimizing the metabolomic protocol is an essential step mics, and proteomics, metabolomics focuses on investigating biological activities and is relatively easier to relate to the phenotype [137]. For example, targeted metabolomics can be optimized to increase the signal-to-noise $(\mathrm{s} / \mathrm{n})$ ratio of the desired metabolite or decrease the time and cost of experimentation [136]. The untargeted approach must be optimized for reproducibility of the protocol to detect the ratio of the actual variation in a biological sample to the variation due to experimental errors. Several approaches, such as fractional factorial analysis or D-Optimal design to experimental design, can optimize metabolomic protocols [136].

\subsection{Analytical and data processing techniques in crop metabolomics}

Several techniques, e.g., gas chromatography mass spectrometry (GC-MS) [144], liquid chromatography mass spectrometry (LC-MS) [145], capillary electrophoresis mass spectrometry (CE-MS) [146], nuclear magnetic resonance (NMR) [147], and vibrational spectroscopy (VS) [136] have been applied in crop metabolomic studies. Table 6 provides 
an overview of commonly used analytical techniques along with their advantages and limitations. With recent advancements in technology, other methods such as gas chromatography time-of-flight mass spectrometry (GC-TOF-MS) [148], ultra-performance liquid chromatography mass spectrometry (UPLC-MS) [149], capillary electrophoresis time-offlight mass spectrometry (CE-TOF-MS) [150], high-performance liquid chromatography (HPLC) [151], liquid chromatography high-resolution mass spectrometry (LC-HRMS) [152] have been utilized in crop metabolomic studies.

Table 2. Overview of most commonly used analytical techniques in metabolomics

\begin{tabular}{|c|c|c|c|}
\hline Technique & Description & Advantages & Limitations \\
\hline LC-MS & $\begin{array}{l}\text { Allows profiling of secondary metabolites such } \\
\text { as alkaloids, flavonoids, phenylpropanoids } \\
\text { based on their different partitioning coefficients } \\
\text { between the mobile phase (solvent) and station- } \\
\text { ary phase (column) }\end{array}$ & $\begin{array}{l}\text { Allow detection of metabolites } \\
\text { without prior derivatization } \\
\text { Useful for both reactive and } \\
\text { thermally stable metabolites } \\
\text { High sensitivity to ionized } \\
\text { metabolites } \\
\text { High mass accuracy allows the } \\
\text { identification of unknown } \\
\text { compounds } \\
\text { A larger sample such as } 1-50 \mathrm{ml} \\
\text { can be used }\end{array}$ & $\begin{array}{l}\text { - High variability } \\
\text { in retention } \\
\text { times } \\
\text { - Difficult to } \\
\text { ionize volatile } \\
\text { metabolites } \\
\text { Low resolution } \\
\text { as compared to } \\
\text { GC } \\
\text { High cost }\end{array}$ \\
\hline CE-MS & $\begin{array}{l}\text { Detect and separate polar or charged metabo- } \\
\text { lites such as inorganic ions, organic acids, amino } \\
\text { acids, vitamins, nucleotides and nucleosides, } \\
\text { thiols, carbohydrates, and peptides based on } \\
\text { their charge and size }\end{array}$ & $\begin{array}{l}\text { Allow rapid analyses with } \\
\text { higher resolution than in LC } \\
\text { Allow separation of polar or } \\
\text { charged metabolites which are } \\
\text { incompatible with LC and GC } \\
\text { Can use heterogeneous samples } \\
\text { Simple sample preparation than } \\
\text { in GC and LC } \\
\text { Low reagent use and low cost } \\
\text { Less quantity of sample, up to } 1 \\
\text { ul can be used }\end{array}$ & 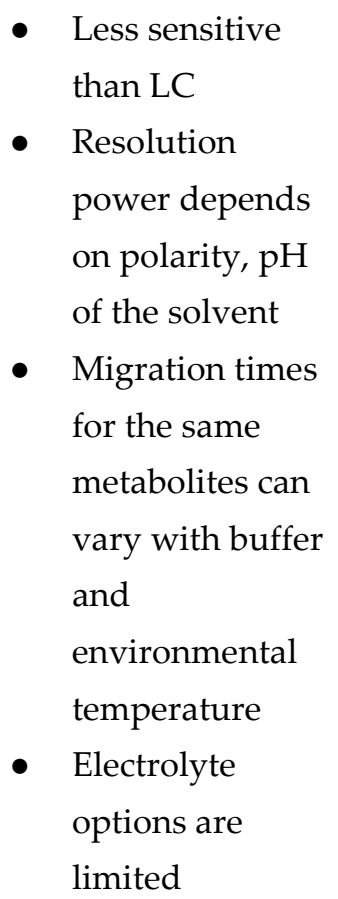 \\
\hline GC-MS & $\begin{array}{l}\text { Allow the simultaneous separation and detec- } \\
\text { tion of a large number of volatile, thermally sta- } \\
\text { ble compounds and primary metabolites such as } \\
\text { sugars, amino acids, organic acids, polyamines } \\
\text { in complex mixtures }\end{array}$ & $\begin{array}{l}\text { High resolution } \\
\text { High sensitivity towards non- } \\
\text { polar and volatile metabolites } \\
\text { than in LC-MS } \\
\text { Low cost than LC-MS }\end{array}$ & 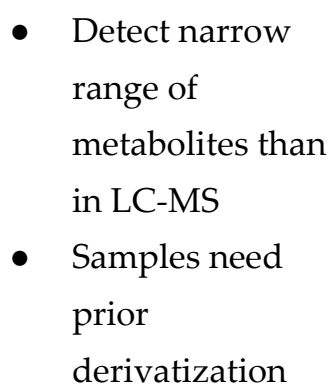 \\
\hline
\end{tabular}


- Low sensitivity

- Allow detection of unknown metabolites

- Less biased and lower

Works on recording the absorption and reemission energy of atom nuclei due to NMR differences in an external magnetic field experimental error than in MS-

based methods

- Easy sample preparation than in MS methods

- Excellent compound coverage

- Less destructive sampling

- Highly utilized in untargeted metabolomics profiling than MS-based

methods

- Detect only the most abundant metabolites

- Need expensive, NMR suitable solvents

- Expensive than most MS-based methods

- Medium reproducibility

- Non-destructive method

- Minimal to no sample

Measures slight differences in vibrational behavpreparation ior of organic functional groups and chemical bonding under electromagnetic (EM) radiation
- Reveals limited structural information

- Poor resolution
Excell Allent compound coverage profiling with high accuracy High reproducibility

After analytical analyses with one or more of the techniques mentioned above, the data then undergoes a series of pre-processing steps, including cleaning, noise reduction, baseline correction, alignment, peak deconvolution, normalization, and scaling. Numerous online platforms have been developed to help metabolomics, data mining, data assessment, data processing, and data interpretation. Different automated and/or semi-automated peak detection methods such as Compare, COMSPARI, LineUp, MarVis, MarkerLynx, MetAlign MarkerView, Metabolic Profiler, MET-IDEA, MSFACTs, MathDAMP, MZmine, Profile, Sieve can be used for data processing [138,153]. Statistical analyses, e.g., principal component analysis (PCA), multivariate curve resolution (MCR), hierarchical cluster analysis (HCA), partial least squares discriminant analysis (PLS-DA), and batchlearning self-organizing map (BL-SOM), are commonly used to make meaningful inferences from large metabolomics datasets $[138,154,155]$. After profiling metabolites in a particular plant species, metabolic pathways can be reconstructed from a list of functionally annotated genes available from the databases, such as KEGG pathway or KNApSAcK $[156,157]$.

\subsection{Applications of metabolomics for crop improvement}

Metabolomics has widely been used to investigate the plant's adaptive responses against stresses. It plays an essential role in investigating the synthesis of specific metabolites under various stresses to understand how plants adapt to unfavorable surroundings. Metabolomic studies uncover new compounds and novel metabolic pathways that accumulate under different stress conditions [140]. Besides, metabolomics studies also help in improving the understanding of previously recognized metabolic pathways. Over the last decade, several metabolome studies have been conducted to investigate the metabolite concentration changes under various biotic and abiotic stress factors, as described in (Table 7). The drought stress response has also been studied by metabolomic approaches in rice [144], wheat [149], maize [148], and sorghum [158]. Variations in phytohormones and other metabolites in the roots of barley plants under salinity stress were reported by Cao et al. 
(2017). In rice, profiles of flavone-glycosides, which are major secondary metabolites, were evaluated against abiotic stress and herbivores [159]. Researchers have reported natural metabolic variations in rice [160]. Moreover, identifying the metabolites encoding for specific loci can potentially be utilized as biomarkers in association studies [140]. Metabolome quantitative trait loci (mQTLs) analysis investigates metabolite concentrations in plant tissues (m-trait) and can, therefore, provide a comprehensive understanding of their genetic background. Furthermore, mQTL can discover novel relationships between metabolomic pathways, structural genes, and agronomically important traits, hence can assist in crop breeding. For example, Chen et al. (2014) have provided a comparative mQTL mapping between rice and maize.

\subsection{Challenges and prospects in metabolomics}

Integrating metabolomics with genetic approaches can facilitate the study of genetic regulation of plants in relation to metabolomics. Furthermore, utilizing high throughput genome sequencing, reverse genetics with metabolomics tools can decrease the development time, such as in metabolomics-assisted breeding. These novel plant breeding approaches can help crop improvement programs produce high-yielding crops, stress-tolerant germplasm, and climate-adapted crop varieties. The combination of metabolomics and other omics technologies such as transcriptomics, proteomics, phenomics, and genomics can investigate complex metabolomic pathways in plants. Metabolic profiling combined with genome-wide prediction studies can be utilized to screen desirable agronomic traits in genotypes and hybrids by genetic mapping, thus opening new opportunities to enhance crop genetics (Wen et al. 2014). Furthermore, genome-wide association studies combined with metabolic and gene-expression studies can explore the environmental effects of plants' phenotype plasticity under various biotic and abiotic conditions [161].

Prospects of metabolomics may include screening the metabolic markers to understand plant metabolism. New emerging technologies such as single-cell metabolomics, metabolome-scale labeling will improve metabolite interpretation, metabolic pathway elucidation, and metabolite quantification at the single-cell level [162]. Recent technological advancements such as the single-probe MS technique has potential for near in situtargeted metabolomic analyses with minimum cell manipulation at the cellular level [163]. Future challenges of metabolomics would be to better utilize the available information from metabolomics and interpret the metabolite information correctly for possible applications

Table 7. Metabolomic studies investigating the crop response to biotic and abiotic stresses.

\begin{tabular}{cccc}
\hline Crop name & Stress & Techniques & References \\
\hline Abiotic stress & & & \\
\hline Rice & Flooding & GC-MS, NMR & {$[164]$} \\
Rice & Drought & GC-MS & {$[144]$} \\
Rice & Low temperature & LC-MS/MS & {$[165]$} \\
\hline Wheat & Drought & UPLC-MS & {$[149]$} \\
Wheat & Low nitrogen & UPLC-QTOF-MS & {$[166]$} \\
\hline Maize & Salinity & NMR & {$[167]$} \\
Maize & Drought & GC-TOF-MS & {$[148]$} \\
Maize & Low nitrogen & GC-MS & {$[168]$} \\
\hline Barley & Salinity & LC-MS & {$[145]$} \\
Barley & Drought & GC-MS & {$[169]$} \\
\hline Sorghum & Drought & GC-MS & {$[158]$} \\
Sorghum & Low nitrogen & GC-MS/LC-MS & {$[170]$} \\
\hline
\end{tabular}




\begin{tabular}{cccc}
\hline Biotic stress & & & \\
\hline Rice & Magnoporthe grisea & NMR, GC/LC-MS/MS & {$[147]$} \\
Rice & Rhizoctonia solani & GC-MS & {$[150]$} \\
\hline Wheat & Stagonospora nodorum & GC-MS & {$[171]$} \\
\hline Maize & Fusarium verticillioides & LC-HRM & {$[172]$} \\
\hline Barley & Fusarium graminearum & HPLC, LC-HRMS & {$[151]$} \\
Barley & Gibberella zeae & LC-MS & {$[173]$} \\
Sorghum & Burkholderia andropogonis & LC-MS & {$[174]$} \\
\hline
\end{tabular}

\section{Phenomics for crop improvement}

During the last two decades, genomics has revolutionized plant breeding mainly due to a reduction in genotyping costs, which results in the adoption of new technologies such as linkage mapping, genome-wide association studies, genomic selection, and rapid generation advance [175]. Accurate genetic mapping and genome-wide selection require precise phenotyping of the plants. However, plant phenomics, i.e., applying tools and methodologies to study plant growth, development, performance, and composition, as a field is still in its infancy and, therefore, has lagged in comparison to genomics [176]. Since the conventional field phenotyping employed by the majority of the plant breeders is laborintensive, costly, and subjective [177]. Plant phenomics is a rapidly expanding domain that ranges from high throughput field phenotyping to cellular level imaging. Nevertheless, during the last decade, more focus was given to the field-based high throughput phenotyping (HTP), primarily, to predict agronomic and physiological traits [178]. In this regard, HTP has demonstrated its potential for non-destructive phenotyping of the various agronomic, physiological, as well as biotic, and abiotic stress-related traits (Kefauver et al. 2017) via (1) utilizing high-throughput tools and platforms, (2) image processing and implementing algorithms for the extraction of raw data, and (3) linking to the processed data to the target traits [179].

Various aerial or ground based HTP platforms have been developed for measuring different plant traits at different growth stages with more precision, throughput, and accuracy [180]. As shown in Table 8, these platforms demonstrated their superiority in rice, wheat, maize, barley, and sorghum (Tables 9, 10). Figure 7 outlines the most used sensors, data analysis methods for managing various stresses in the five most important cereals, namely, rice wheat, maize, barley, and sorghum. The development of novel imaging sensors for non-invasively phenotyping a wide range of organs, tissues, and physiological processes has provided a substantial impetus to the HTP [181]. This section of the review concentrates on (1) various phenotyping platforms that are currently being used to accelerate genetic gains in key cereals viz., rice, wheat, maize, barley, and sorghum, (2) advancements in imaging sensors and subsequent analyses, and (3) application of machine and deep learning methods for solving the "big data" problems in phenomics.

\subsection{Plant phenotyping platforms}

HTP depends on the imaging sensor used. Advanced phenotyping platforms have improved the data capture capabilities by including mobility, throughput, and inbuilt data storage at relatively low cost. Unmanned aerial vehicles (UAVs) have maximum adoption due to their reliability, cost, and technical requirements; however, some countries are still not adopting it due to regulations controlling their flight. Several carts and tractor-mounted tools have similarly been adopted for various crops, although their utilization is also stage-dependent [176]. Moreover, several handheld cheap platforms provide spectral and time-series information. However, these handheld devices face issues of standardization and low throughput; and, because they are usually mounted over poles, they result in less canopy coverage [182]. Table 8 provides detailed information about various platforms utilized during the last decade. 
Table 8. List of phenotyping platforms and their utilization.

\begin{tabular}{lll}
\hline \multicolumn{1}{c}{$\begin{array}{c}\text { Phenotyping platform/ } \\
\text { techniques }\end{array}$} & \multicolumn{1}{c}{ Utilization } & References \\
\hline BreedVision & $\begin{array}{l}\text { Tractor-pulled multisensory phenotyping platform with RGB, mul- } \\
\text { tispectral, and time of flight sensors }\end{array}$ & [182] \\
Grow screen fluoro & $\begin{array}{l}\text { Work under controlled conditions for quantification of fluorescence } \\
\text { pigments }\end{array}$ & [183] \\
Leaf curtain arrays & Utilized for leaf area and plant height estimation & [184] \\
LEAF-E & Estimates the total leaf growth and rate of development & [185] \\
Phenocart & $\begin{array}{l}\text { A movable platform in the field used for high throughput pheno- } \\
\text { typing }\end{array}$ & [178] \\
Phenopsis & Used to study drought tolerance abilities under control conditions & [186] \\
Phenoplant & $\begin{array}{l}\text { Used to obtain chlorophyll fluorescence parameters under con- } \\
\text { trolled conditions }\end{array}$ & [187] \\
Psed for phenotyping a large number of samples under controlled \\
conditions by providing fluorescence, multispectral and RGB im- \\
ages
\end{tabular}

\subsection{Imaging sensors and analysis}

Imaging sensors have enabled the collection of high-resolution and multidimensional data from plants to quantify plant growth, yield, stress, and physiological process under both control and field conditions. The recent development of sensors technology measuring reflection from gamma rays to radio waves regions of the electromagnetic spectrum has provided a plethora of information to plant scientists. These imaging sensors vary from spectroscopy, sound navigation ranging (SONAR), light detection and ranging (LIDAR), X-ray computed tomography (CT), thermal, visible to near-infrared, multispectral, hyperspectral, fluorescence, time of flight (ToF), positron emission tomography, stereovision $[188,190]$. The utilization of these imaging sensors with autonomous platforms has opened up the doors of HTP. Tables 9 and 10 provide detailed information about different imaging sensors utilized for studying agronomic traits, biotic and abiotic stresses in the five most important crops: rice, wheat, maize, barley, and sorghum grown in the world.

\subsubsection{RGB/visible imaging}

RGB cameras or regular cameras, or digital cameras capture the true color images in the electromagnetic spectrum's visible region. This is the cheapest and most often used senor for plant phenotyping studies. These sensors reflect the red, green, and blue regions of the visible spectrum. It has been used to estimate plant biomass, different pigments, 
tiller count, yield traits, flowering time, biotic stresses, plant height, germination, and emergence rates [192,193].

\subsubsection{Multispectral imaging}

Multispectral cameras provide information about specific wavelength bands from the spectrum's visible and infrared regions. These reflection bands are used to extract different vegetation bands, which give information about photosynthetic efficiency, pigments, nutrient status, water status, and plant senescence [194]. The essential indices utilized include normalized differentiation vegetation index (NDVI), water index (WI), anthocyanin reflection index (ARI), and simple ratio (SR) [195].

\subsubsection{Hyperspectral imaging}

These imaging sensors cover whole visible and infrared regions with a high spatial resolution by covering reflection from the entire areas due to the sensor's small band width. These sensors have the best spatial and spectral resolution, resulting in more useful information. This imaging platform has been used for studying plant health status, leaf growth, predicting grain yield, biotic stresses, water status, plant height, and chlorophyll content $[195,196]$.

\subsubsection{Thermal imaging}

These sensors provide information about plant water status by measuring reflection from the infrared region for estimating canopy temperature and transpiration rate. Thermal imaging has been used for detecting plant water status, disease-infected plants, and maturity of the fruits $[197,198]$.

\subsubsection{Fluorescence imaging}

Fluorescence sensors provide information about photochemistry changes by capturing photosystem II's fluorescence emissions. Plants absorb a specific portion of the electromagnetic spectrum and thus have a characteristic emission spectrum. Fluorescence sensors provide information about the photosynthesis rate, chlorophyll content, and various physiological processes in plants [199].

\subsubsection{X-ray computed tomography}

These imaging sensors aid in the generation of 3D tomographic images of the objects using an extensive series of 2D radiographic images taken with computer-processed Xrays. Images provide root architectures by separating objects depending on the different densities. X-ray CT has been utilized for studying root traits, tillers morphology, and grain quality $[179,200]$.

In addition to all these imaging sensors, there are several others: positron emission tomography, magnetic resonance imaging, SONAR, laser scanning, LIDAR, and flight time. These sensor readings are referred to as other publications [179,195].

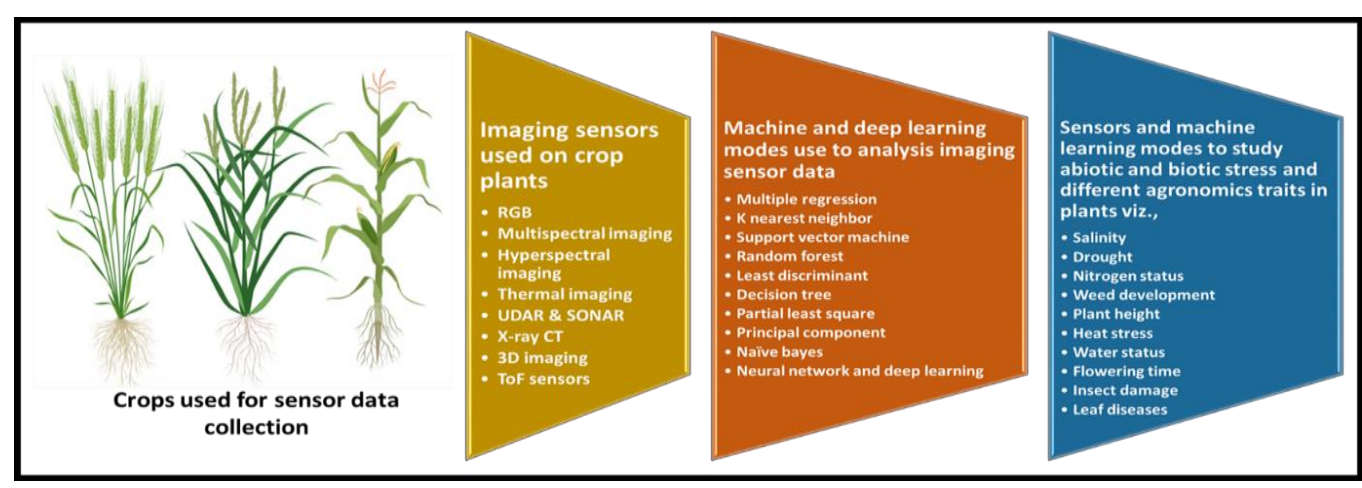


Figure 7. Imaging sensors and respective machine learning models which were used for managing various biotic and abiotic stresses in cereals are provided.

Table 9. Application of high throughput phenotyping platforms and imaging sensors for improving abiotic stresses and agronomic traits in field crops during the last decade.

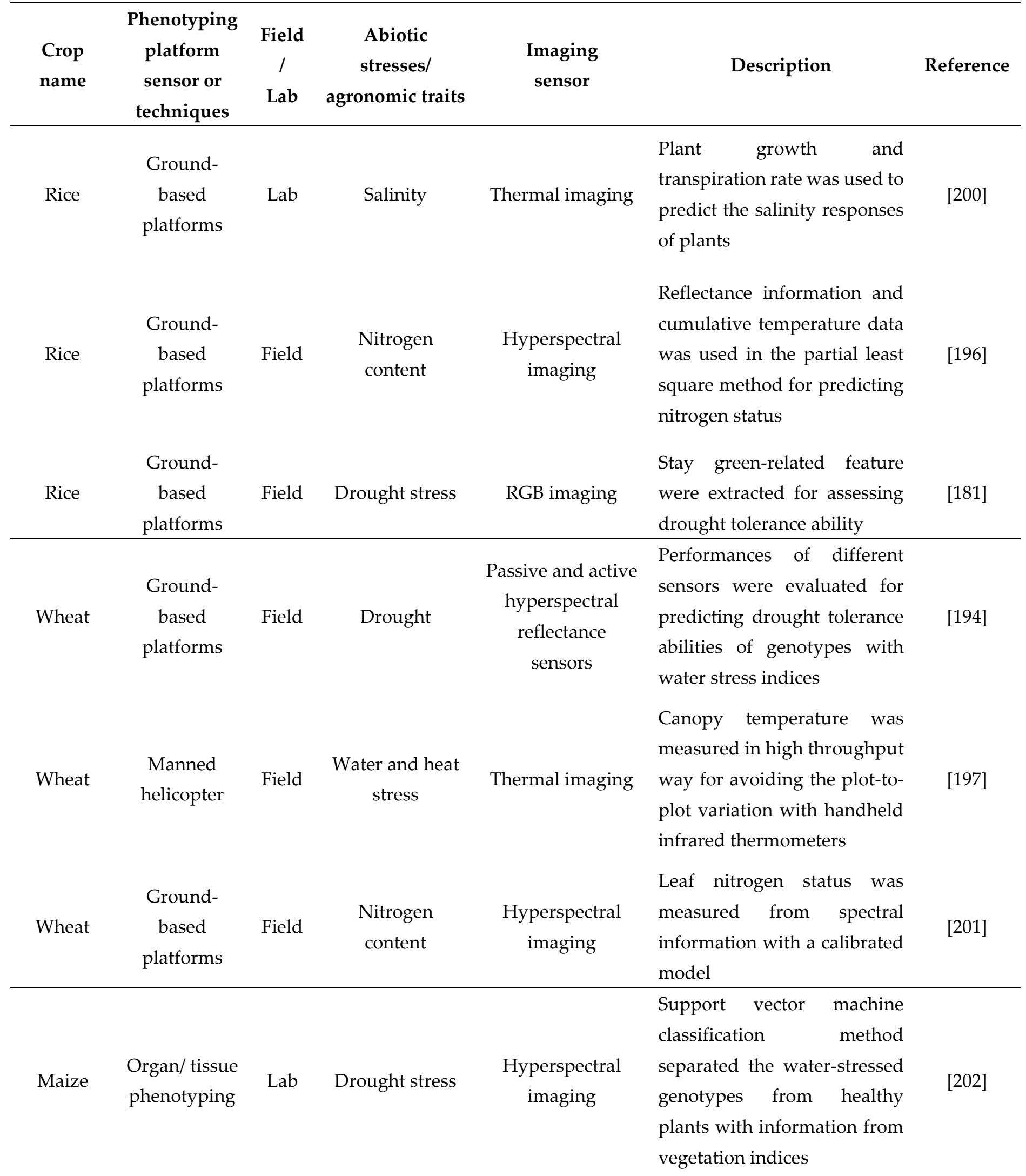


Crop water stress index was

$\begin{array}{cccc}\text { Mnmanned } & \text { Field } & \text { Water status in } & \text { Multispectral and } \\ \text { aerial vehicle } & \text { plants } & \text { thermal imaging }\end{array}$

predicted from the multispectral images to decipher the plant water status

Loss of greenness from maize

$\begin{array}{ccccc}\text { Maize } & \begin{array}{c}\text { Unmanned } \\ \text { aerial vehicle }\end{array} & \text { Field } & \text { Weeds } & \text { RGB imaging } \\ \text { Barley } & \begin{array}{c}\text { Ground- } \\ \text { based } \\ \text { platforms }\end{array} & \text { Field } & \text { Drought } & \begin{array}{c}\text { Hyperspectral } \\ \text { imaging }\end{array}\end{array}$
was used for separating weeds from the plants

Linear ordinal support vector machine model was used to predict the drought responses in the plants

Infrared imaging was used to

Organ/tissue
Bhenotyping Lab Salinity Thermal imaging

differentiate salt

concentration among the genotypes

RGB,
ispectral and
mal imaging

UAV's having RGB, multispectral and thermal imaging was utilized for nitrogen use efficiency

\begin{tabular}{|c|c|c|c|c|c|c|}
\hline Sorghum & $\begin{array}{l}\text { Ground- } \\
\text { based } \\
\text { platforms }\end{array}$ & Field & Plant height & $\begin{array}{l}\text { RGB, ultrasonic, } \\
\text { and LIDAR } \\
\text { sensor }\end{array}$ & $\begin{array}{l}\text { A comparison was performed } \\
\text { for predicting sorghum } \\
\text { height, with the LIDAR } \\
\text { sensor performing best }\end{array}$ & [205] \\
\hline Sorghum & $\begin{array}{c}\text { Unmanned } \\
\text { aerial vehicle }\end{array}$ & Field & Drought stress & RGB imaging & $\begin{array}{l}\text { Plant height, biomass, and } \\
\text { leaf area were measured for } \\
\text { assessing the drought- } \\
\text { tolerant abilities of genotypes }\end{array}$ & [206] \\
\hline
\end{tabular}

Table 10. Application of high throughput phenotyping platforms and imaging sensors for improving biotic stresses in field crops during the last decade.

\begin{tabular}{|c|c|c|c|c|c|c|}
\hline Crop & $\begin{array}{c}\text { Phenotyping } \\
\text { platform/ sensor/ } \\
\text { techniques }\end{array}$ & $\begin{array}{c}\text { Field/ } \\
\text { Lab }\end{array}$ & $\begin{array}{c}\text { Disease/ } \\
\text { Pest/ } \\
\text { Virus }\end{array}$ & Imaging sensor & Description & References \\
\hline Rice & $\begin{array}{c}\text { Ground and } \\
\text { aerial platforms }\end{array}$ & $\begin{array}{c}\text { Field/ } \\
\text { Lab }\end{array}$ & Rice blast & $\begin{array}{l}\text { Multispectral } \\
\text { imaging }\end{array}$ & $\begin{array}{l}\text { Reflectance values were } \\
\text { correlated with the } \\
\text { disease severity }\end{array}$ & [207] \\
\hline
\end{tabular}




\begin{tabular}{|c|c|c|c|c|c|c|}
\hline Rice & $\begin{array}{l}\text { Organ/tissue } \\
\text { phenotyping }\end{array}$ & $\mathrm{Lab}$ & Alfatoxin & $\begin{array}{l}\text { Near-infrared } \\
\text { spectroscopy }\end{array}$ & $\begin{array}{l}\text { Partial least regression } \\
\text { utilized reflectance } \\
\text { information for } \\
\text { separating infected and } \\
\text { healthy seeds }\end{array}$ & [208] \\
\hline Rice & $\begin{array}{c}\text { Unmanned aerial } \\
\text { vehicle }\end{array}$ & Field & $\begin{array}{l}\text { Rice } \\
\text { sheath } \\
\text { blight }\end{array}$ & $\begin{array}{c}\text { RGB and } \\
\text { multispectral } \\
\text { imaging }\end{array}$ & $\begin{array}{l}\text { Percentage of infected } \\
\text { leaves from RGB images } \\
\text { and vegetation indices } \\
\text { from multispectral } \\
\text { imaging aid in the } \\
\text { detection of rice sheath } \\
\text { blight }\end{array}$ & [209] \\
\hline Wheat & $\begin{array}{c}\text { Ground-based } \\
\text { platforms }\end{array}$ & Field & $\begin{array}{c}\text { Septoria } \\
\text { tritici } \\
\text { blotch }\end{array}$ & $\begin{array}{c}\text { Hyperspectral } \\
\text { imaging }\end{array}$ & $\begin{array}{l}\text { Spectral reflectance } \\
\text { indices derived from } \\
\text { hyperspectral imaging } \\
\text { aids in detecting the } \\
\text { presence and severity of } \\
\text { Septoria tritici blotch }\end{array}$ & [175] \\
\hline Wheat & $\begin{array}{l}\text { Organ/tissue } \\
\text { phenotyping }\end{array}$ & $\mathrm{Lab}$ & $\begin{array}{c}\text { Fusarium } \\
\text { head } \\
\text { blight }\end{array}$ & $\begin{array}{c}\text { Hyperspectral } \\
\text { imaging }\end{array}$ & $\begin{array}{l}\text { Fusarium head blight } \\
\text { was detected using } \\
\text { visible-NIR imaging of } \\
\text { wheat grain, and grains } \\
\text { were separated using } \\
\text { linear discrimination } \\
\text { and principal } \\
\text { component analysis }\end{array}$ & [210] \\
\hline Wheat & $\begin{array}{c}\text { Unmanned aerial } \\
\text { vehicle }\end{array}$ & Field & $\begin{array}{l}\text { Yellow } \\
\text { rust }\end{array}$ & $\begin{array}{c}\text { Hyperspectral } \\
\text { imaging }\end{array}$ & $\begin{array}{l}\text { Deep convolutional } \\
\text { neural network utilizing } \\
\text { both spectral and spatial } \\
\text { resolution provided the } \\
\text { best performance for } \\
\text { predicting yellow rust }\end{array}$ & [211] \\
\hline
\end{tabular}

$\begin{array}{cccccc}\text { Maize } & \text { Ground and } & \text { Northern } & & \text { A convolutional neural } \\ \text { aerial platforms } & \text { Field } & \begin{array}{c}\text { leaf } \\ \text { blight }\end{array} & \text { RGB imaging } & \begin{array}{l}\text { network was used for } \\ \text { classifying the infected }\end{array} \\ & & & \text { leaves }\end{array}$




\begin{tabular}{|c|c|c|c|c|c|c|}
\hline Maize & $\begin{array}{l}\text { Organ/tissue } \\
\text { phenotyping }\end{array}$ & $\mathrm{Lab}$ & $\begin{array}{l}\text { Alfatoxin } \\
\text { infection }\end{array}$ & $\begin{array}{l}\text { Fluorescence } \\
\text { imaging }\end{array}$ & $\begin{array}{l}\text { Discriminant analysis } \\
\text { from the imaging data } \\
\text { aids in the separation of } \\
\text { healthy and affected } \\
\text { kernels }\end{array}$ & [199] \\
\hline Maize & $\begin{array}{l}\text { Unmanned aerial } \\
\text { vehicle }\end{array}$ & $\mathrm{Lab}$ & Tar spot & $\begin{array}{l}\text { Multispectral and } \\
\text { thermal imaging }\end{array}$ & $\begin{array}{l}\text { Disease progression } \\
\text { curved was analyzed } \\
\text { using vegetation indices } \\
\text { derived from the images }\end{array}$ & [213] \\
\hline Barley & $\begin{array}{l}\text { Ground-based } \\
\text { platforms }\end{array}$ & Field & $\begin{array}{l}\text { Powdery } \\
\text { mildew }\end{array}$ & $\begin{array}{l}\text { Hyperspectral } \\
\text { imaging }\end{array}$ & $\begin{array}{l}\text { Support vector machine } \\
\text { was used for early } \\
\text { detecting the disease } \\
\text { symptoms } \\
\text { measuring reflection } \\
\text { bands }\end{array}$ & [214] \\
\hline Barley & $\begin{array}{l}\text { Ground-based } \\
\text { platforms }\end{array}$ & Field & Blast & $\begin{array}{l}\text { Hyperspectral } \\
\text { imaging }\end{array}$ & $\begin{array}{l}\text { Spectral angle mapping } \\
\text { and spectral unmixing } \\
\text { analysis was used to } \\
\text { locate the pathogen } \\
\text { lesions }\end{array}$ & [193] \\
\hline Barley & $\begin{array}{l}\text { Organ/ tissue } \\
\text { phenotyping }\end{array}$ & $\mathrm{Lab}$ & $\begin{array}{l}\text { Rust and } \\
\text { powdery } \\
\text { mildew }\end{array}$ & $\begin{array}{l}\text { Hyperspectral } \\
\text { imaging }\end{array}$ & $\begin{array}{l}\text { A simple volume } \\
\text { maximization algorithm } \\
\text { was developed for } \\
\text { differentiating different } \\
\text { infected leaves }\end{array}$ & [192] \\
\hline
\end{tabular}

\subsection{Challenges and prospectus in crop phenomics}

The continuous use of aerial and ground based HTP platforms with different imaging sensors at multiple points during different growth stages of the plants has resulted in big data, storage issues, and extraction of valuable information. This issue is resolved by adopting the machine and deep learning tools for data analysis to extract legitimate conclusions from the big data sets [179]. Machine learning (ML) is an interdisciplinary approach for data analysis using probability, statistics, classification, regression, decision theory, data visualization, and neural networks to relate information extracted with the phenotyped obtained. ML provides a significant advantage to the plant breeders, pathologists, and agronomists for the extraction of many parameters for analyzing each trait together, despite traditionally where we just used to look at a single feature at a time [205]. The other great breakthrough with ML is directly linking the variables extracted from the HTP data to the plant stresses, biomass accumulation, grain yield, and soil characteristics $[206,215]$. ML's biggest success involves inferring trends from the data and generalizing the results by training the model. There have been various ML models being applied for HTP, namely support vector machine [204], discriminant analysis [210], $\mathrm{k}$ means clustering [195], neural network [211], clustering [195], and dimensional reduction [179]. All these models help identify, classify, quantify, and predict different phenotyping components in plants. 
However, the recent transformation by deep learning (DL) in other fields such as traffic signaling, health care, voice and image recognition, consumer analytics, and medical diagnostics has provided a new tool to plant scientists for image analysis in HTP [215]. DL models involve automatically learning the pattern from the extensive data set using non-linear activation functions for making conclusions such as classification or predictions. The important DL models used for phenomics include but are not limited to a multilayer perceptron, generative adversarial networks, convolutional neural network, and recurrent neural network [212]. These potential data analysis tools open up a new path for opening the prospectus of HTP in plant breeding.

Overall, in this phenomics section, we provided a comprehensive review of the advent of high throughput phenotyping, aerial and ground-based platforms, imaging sensors and analysis, and finally, data analysis methods and phenotyping bottlenecks and prospectus to deliver the whole pipeline of the HTP utilization in the programs.

Supplementary Materials: The following are available online at www.mdpi.com/xxx/s1, Figure S1: title, Table S1: title, Video S1: title.

Author Contributions: BK and KSS conceived the idea. QHM and RK outlined the manuscript. BK, KSS, RK, KK, JS, and QHM contributed to the writing of the manuscript. RK contributed to figure editing. QHM, MSR, and RK edited the manuscript. All authors have read and agreed to the published version of the manuscript.

Funding: This research received no external funding.

Institutional Review Board Statement: Not applicable.

Informed Consent Statement: Not applicable.

Data Availability Statement: Data is contained within the article.

Acknowledgments: RK thanks drawing tool BioRender that helped create the crop images in Figs. 1 and 7.

Conflicts of Interest: The authors declare no conflict of interest.

\section{References}

1. Röder, M.S.; Korzun, V.; Wendehake, K.; Plaschke, J.; Tixier, M.-H.; Leroy, P.; Ganal, M.W. A microsatellite map of wheat. Genetics 1998, 149, 2007-2023.

2. Bernardo, R. Breeding for quantitative traits in plants. Press S, editor. Woodbury: 2010.

3. Ganal, M.W.; Plieske, J.; Hohmeyer, A.; Polley, A.; Röder, M.S. High-throughput genotyping for cereal research and breeding. In Applications of Genetic and Genomic Research in Cereals, Elsevier: 2019; pp. 3-17.

4. Rabanus-Wallace, M.T.; Stein, N. Progress in sequencing of Triticeae genomes and future uses. In Applications of Genetic and Genomic Research in Cereals, Elsevier: 2019; pp. 19-47.

5. Goff, S.A.; Ricke, D.; Lan, T.-H.; Presting, G.; Wang, R.; Dunn, M.; Glazebrook, J.; Sessions, A.; Oeller, P.; Varma, H. A draft sequence of the rice genome (Oryza sativa L. ssp. japonica). Science (New York, N.Y.) 2002, 296, 92-100.

6. Yu, J.; Hu, S.; Wang, J.; Wong, G.K.-S.; Li, S.; Liu, B.; Deng, Y.; Dai, L.; Zhou, Y.; Zhang, X. A draft sequence of the rice genome (Oryza sativa L. ssp. indica). Science (New York, N.Y.) 2002, 296, 79-92.

7. Paterson, A.H.; Bowers, J.E.; Bruggmann, R.; Dubchak, I.; Grimwood, J.; Gundlach, H.; Haberer, G.; Hellsten, U.; Mitros, T.; Poliakov, A. The Sorghum bicolor genome and the diversification of grasses. Nature 2009, 457, 551-556.

8. Schnable, P.S.; Ware, D.; Fulton, R.S.; Stein, J.C.; Wei, F.; Pasternak, S.; Liang, C.; Zhang, J.; Fulton, L.; Graves, T.A. The B73 maize genome: complexity, diversity, and dynamics. Science (New York, N.Y.) 2009, 326, 1112-1115.

9. $\quad$ Alexandrov, N.; Tai, S.; Wang, W.; Mansueto, L.; Palis, K.; Fuentes, R.R.; Ulat, V.J.; Chebotarov, D.; Zhang, G.; Li, Z. SNPSeek database of SNPs derived from 3000 rice genomes. Nucleic acids research 2015, 43, D1023-D1027. 
10. Żmieńko, A.; Samelak, A.; Kozłowski, P.; Figlerowicz, M. Copy number polymorphism in plant genomes. Theoretical and applied genetics 2014, 127, 1-18.

11. Saxena, R.K.; Edwards, D.; Varshney, R.K. Structural variations in plant genomes. Brief Funct Genomics 2014, 13, 296-307, doi:10.1093/bfgp/elu016.

12. Wang, Y.; Xiong, G.; Hu, J.; Jiang, L.; Yu, H.; Xu, J.; Fang, Y.; Zeng, L.; Xu, E.; Xu, J. Copy number variation at the GL7 locus contributes to grain size diversity in rice. Nature genetics 2015, 47, 944-948.

13. Würschum, T.; Boeven, P.H.; Langer, S.M.; Longin, C.F.H.; Leiser, W.L. Multiply to conquer: copy number variations at Ppd-B1 and Vrn-A1 facilitate global adaptation in wheat. BMC genetics 2015, 16, 96.

14. Teplyakova, S.; Lebedeva, M.; Ivanova, N.; Horeva, V.; Voytsutskaya, N.; Kovaleva, O.; Potokina, E. Impact of the 7-bp deletion in HvGA20ox2 gene on agronomic important traits in barley (Hordeum vulgare L.). BMC Plant Biology 2017, 17, 181, doi:10.1186/s12870-017-1121-4.

15. Yu, J.; Buckler, E.S. Genetic association mapping and genome organization of maize. Current opinion in biotechnology 2006, $17,155-160$.

16. Guo, T.; Yang, J.; Li, D.; Sun, K.; Luo, L.; Xiao, W.; Wang, J.; Liu, Y.; Wang, S.; Wang, H. Integrating GWAS, QTL, mapping and RNA-seq to identify candidate genes for seed vigor in rice (Oryza sativa L.). Molecular Breeding 2019, $39,87$.

17. Kim, S.-M.; Reinke, R.F. A novel resistance gene for bacterial blight in rice, Xa43 (t) identified by GWAS, confirmed by QTL mapping using a bi-parental population. PloS one 2019, 14, e0211775.

18. Kang, J.-W.; Kabange, N.R.; Phyo, Z.; Park, S.-Y.; Lee, S.-M.; Lee, J.-Y.; Shin, D.; Cho, J.H.; Park, D.-S.; Ko, J.-M. Combined Linkage Mapping and Genome-Wide Association Study Identified QTLs Associated with Grain Shape and Weight in Rice (Oryza sativa L.). Agronomy 2020, 10, 1532.

19. Yano, K.; Morinaka, Y.; Wang, F.; Huang, P.; Takehara, S.; Hirai, T.; Ito, A.; Koketsu, E.; Kawamura, M.; Kotake, K., et al. GWAS with principal component analysis identifies a gene comprehensively controlling rice architecture. Proceedings of the National Academy of Sciences 2019, 116, 21262-21267, doi:10.1073/pnas.1904964116.

20. Yuan, J.; Wang, X.; Zhao, Y.; Khan, N.U.; Zhao, Z.; Zhang, Y.; Wen, X.; Tang, F.; Wang, F.; Li, Z. Genetic basis and identification of candidate genes for salt tolerance in rice by GWAS. Scientific reports 2020, 10, 1-9.

21. Gao, F.; Wen, W.; Liu, J.; Rasheed, A.; Yin, G.; Xia, X.; Wu, X.; He, Z. Genome-wide linkage mapping of QTL for yield components, plant height and yield-related physiological traits in the Chinese wheat cross Zhou 8425B/Chinese Spring. Frontiers in Plant Science 2015, 6, 1099.

Wu, Q.-H.; Chen, Y.-X.; Zhou, S.-H.; Fu, L.; Chen, J.-J.; Xiao, Y.; Zhang, D.; Ouyang, S.-H.; Zhao, X.-J.; Cui, Y. High-density genetic linkage map construction and QTL mapping of grain shape and size in the wheat population Yanda1817× Beinong6. PloS one 2015, 10, e0118144.

23. Tian, X.; Wen, W.; Xie, L.; Fu, L.; Xu, D.; Fu, C.; Wang, D.; Chen, X.; Xia, X.; Chen, Q. Molecular mapping of reduced plant height gene Rht24 in bread wheat. Frontiers in plant science 2017, 8, 1379.

24. Guo, Z.; Chen, D.; Alqudah, A.M.; Roder, M.S.; Ganal, M.W.; Schnurbusch, T. Genome-wide association analyses of 54 traits identified multiple loci for the determination of floret fertility in wheat. New Phytol 2017, 214, 257-270, doi:10.1111/nph.14342.

25. Muqaddasi, Q.H.; Brassac, J.; Koppolu, R.; Plieske, J.; Ganal, M.W.; Röder, M.S. TaAPO-A1, an ortholog of rice ABERRANT PANICLE ORGANIZATION 1, is associated with total spikelet number per spike in elite European hexaploid winter wheat (Triticum aestivum L.) varieties. Scientific Reports 2019, 9, 1-12.

26. Poland, J.A.; Bradbury, P.J.; Buckler, E.S.; Nelson, R.J. Genome-wide nested association mapping of quantitative resistance to northern leaf blight in maize. Proceedings of the National Academy of Sciences 2011, 108, 6893-6898.

27. Li, X.; Zhou, Z.; Ding, J.; Wu, Y.; Zhou, B.; Wang, R.; Ma, J.; Wang, S.; Zhang, X.; Xia, Z. Combined linkage and association mapping reveals QTL and candidate genes for plant and ear height in maize. Frontiers in plant science 2016, 7, 833. 
28. Wu, X.; Li, Y.; Shi, Y.; Song, Y.; Zhang, D.; Li, C.; Buckler, E.S.; Li, Y.; Zhang, Z.; Wang, T. Joint - linkage mapping and GWAS reveal extensive genetic loci that regulate male inflorescence size in maize. Plant Biotechnology Journal 2016, 14, 15511562.

29. Li, H.; Thrash, A.; Tang, J.D.; He, L.; Yan, J.; Warburton, M.L. Leveraging GWAS data to identify metabolic pathways and networks involved in maize lipid biosynthesis. The Plant Journal 2019, 98, 853-863.

30. Wang, H.; Wei, J.; Li, P.; Wang, Y.; Ge, Z.; Qian, J.; Fan, Y.; Ni, J.; Xu, Y.; Yang, Z. Integrating GWAS and Gene Expression Analysis Identifies Candidate Genes for Root Morphology Traits in Maize at the Seedling Stage. Genes 2019, $10,773$.

31. Wang, J.; Yang, J.; Jia, Q.; Zhu, J.; Shang, Y.; Hua, W.; Zhou, M. A new QTL for plant height in barley (Hordeum vulgare L.) showing no negative effects on grain yield. PLoS One 2014, 9, e90144, doi:10.1371/journal.pone.0090144.

Liller, C.B.; Walla, A.; Boer, M.P.; Hedley, P.; Macaulay, M.; Effgen, S.; von Korff, M.; van Esse, G.W.; Koornneef, M. Fine mapping of a major QTL for awn length in barley using a multiparent mapping population. Theoretical and Applied Genetics 2017, 130, 269-281.

33. Alqudah, A.M.; Sharma, R.; Pasam, R.K.; Graner, A.; Kilian, B.; Schnurbusch, T. Genetic Dissection of Photoperiod Response Based on GWAS of Pre-Anthesis Phase Duration in Spring Barley. PLoS ONE 2014, 9, e113120, doi:10.1371/journal.pone.0113120.

34. Karunarathne, S.D.; Han, Y.; Zhang, X.-Q.; Zhou, G.; Hill, C.B.; Chen, K.; Angessa, T.; Li, C. Genome-wide association study and identification of candidate genes for nitrogen use efficiency in barley (Hordeum vulgare L.). Frontiers in Plant Science 2020, 11, 1361.

35. Thabet, S.G.; Moursi, Y.S.; Karam, M.A.; Börner, A.; Alqudah, A.M. Natural variation uncovers candidate genes for barley spikelet number and grain yield under drought stress. Genes 2020, 11, 533.

36. Zou, G.; Zhai, G.; Feng, Q.; Yan, S.; Wang, A.; Zhao, Q.; Shao, J.; Zhang, Z.; Zou, J.; Han, B. Identification of QTLs for eight agronomically important traits using an ultra-high-density map based on SNPs generated from high-throughput sequencing in sorghum under contrasting photoperiods. Journal of experimental botany 2012, 63, 5451-5462.

37. Boyles, R.E.; Pfeiffer, B.K.; Cooper, E.A.; Rauh, B.L.; Zielinski, K.J.; Myers, M.T.; Brenton, Z.; Rooney, W.L.; Kresovich, S. Genetic dissection of sorghum grain quality traits using diverse and segregating populations. Theoretical and applied genetics 2017, 130, 697-716.

38. Zhao, J.; Mantilla Perez, M.B.; Hu, J.; Salas Fernandez, M.G. Genome - wide association study for nine plant architecture traits in sorghum. The plant genome 2016, 9, 1-14.

39. Rhodes, D.H.; Hoffmann, L.; Rooney, W.L.; Herald, T.J.; Bean, S.; Boyles, R.; Brenton, Z.W.; Kresovich, S. Genetic architecture of kernel composition in global sorghum germplasm. BMC genomics 2017, 18, 1-8.

40. Tao, Y.; Zhao, X.; Wang, X.; Hathorn, A.; Hunt, C.; Cruickshank, A.W.; van Oosterom, E.J.; Godwin, I.D.; Mace, E.S.; Jordan, D.R. Large - scale GWAS in sorghum reveals common genetic control of grain size among cereals. Plant Biotechnology Journal 2020, 18, 1093-1105.

41. Jayakodi, M.; Padmarasu, S.; Haberer, G.; Bonthala, V.S.; Gundlach, H.; Monat, C.; Lux, T.; Kamal, N.; Lang, D.; Himmelbach, A., et al. The barley pan-genome reveals the hidden legacy of mutation breeding. Nature 2020, 10.1038/s41586-020-2947-8, doi:10.1038/s41586-020-2947-8.

42. Jayakodi, M.; Schreiber, M.; Stein, N.; Mascher, M. Building pan-genome infrastructures for crop plants and their use in association genetics. DNA Res 2021, 10.1093/dnares/dsaa030, doi:10.1093/dnares/dsaa030.

43. Zhao, Q.; Feng, Q.; Lu, H.; Li, Y.; Wang, A.; Tian, Q.; Zhan, Q.; Lu, Y.; Zhang, L.; Huang, T. Pan-genome analysis highlights the extent of genomic variation in cultivated and wild rice. Nature genetics 2018, 50, 278-284.

44. Walkowiak, S.; Gao, L.; Monat, C.; Haberer, G.; Kassa, M.T.; Brinton, J.; Ramirez-Gonzalez, R.H.; Kolodziej, M.C.; Delorean, E.; Thambugala, D., et al. Multiple wheat genomes reveal global variation in modern breeding. Nature 2020, 10.1038/s41586020-2961-x, doi:10.1038/s41586-020-2961-x. 
45. Pérez-Ortín, J.E.; Tordera, V.; Chávez, S. Homeostasis in the Central Dogma of molecular biology: the importance of mRNA instability. RNA Biology 2019, 16, 1659-1666.

46. Lowe, R.; Shirley, N.; Bleackley, M.; Dolan, S.; Shafee, T. Transcriptomics technologies. PLoS Computational Biology 2017, 13, e1005457.

47. Sim, G.; Kafatos, F.; Jones, C.; Koehler, M.; Efstratiadis, A.; Maniatis, T. Use of a cDNA library for studies on evolution and developmental expression of the chorion multigene families. Cell 1979, 18, 1303-1316.

48. Singh, J.; Aggarwal, R.; Gurjar, M.; Sharma, S.; Jain, S.; Saharan, M. Identification and expression analysis of pathogenicityrelated genes in Tilletia indica inciting Karnal bunt of wheat. Australasian Plant Pathology 2020, 49, 393-402.

49. Velculescu, V.E.; Zhang, L.; Vogelstein, B.; Kinzler, K.W. Serial analysis of gene expression. Science (New York, N.Y.) 1995, 270, 484-487.

50. Itzkovitz, S.; Van Oudenaarden, A. Validating transcripts with probes and imaging technology. Nature Methods 2011, 8, S12S19.

51. LaFratta, C.N.; Walt, D.R. Very high density sensing arrays. Chemical Reviews 2008, 108, 614-637.

52. Darshan, K.; Aggarwal, R.; Bashyal, B.M.; Singh, J.; Shanmugam, V.; Gurjar, M.S.; Solanke, A.U. Transcriptome profiling provides insights into potential antagonistic mechanisms involved in Chaetomium globosum against Bipolaris sorokiniana. Frontiers in Microbiology 2020, 11.

53. Le Nguyen, K.; Grondin, A.; Courtois, B.; Gantet, P. Next-generation sequencing accelerates crop gene discovery. Trends in Plant Science 2019, 24, 263-274.

54. Knierim, E.; Lucke, B.; Schwarz, J.M.; Schuelke, M.; Seelow, D. Systematic comparison of three methods for fragmentation of long-range PCR products for next generation sequencing. PloS ONE 2011, 6, e28240.

55. Luo, Y.; Hitz, B.C.; Gabdank, I.; Hilton, J.A.; Kagda, M.S.; Lam, B.; Myers, Z.; Sud, P.; Jou, J.; Lin, K. New developments on the Encyclopedia of DNA Elements (ENCODE) data portal. Nucleic Acids Research 2020, 48, D882-D889.

56. Zhang, M.; Hong, L.-Z.; Gu, M.-F.; Wu, C.-D.; Zhang, G. Transcriptome analyses revealed molecular responses of Cynanchum auriculatum leaves to saline stress. Scientific Reports 2020, 10, 1-11.

Ahanger, M.A.; Akram, N.A.; Ashraf, M.; Alyemeni, M.N.; Wijaya, L.; Ahmad, P. Plant responses to environmental stresses-from gene to biotechnology. AoB Plants 2017, 9.

58. Selvi, A.; Devi, K.; Manimekalai, R.; Prathima, P. Comparative analysis of drought-responsive transcriptomes of sugarcane genotypes with differential tolerance to drought. 3 Biotech 2020, 10, 1-14.

Le, D.T.; Nishiyama, R.; Watanabe, Y.; Tanaka, M.; Seki, M.; Yamaguchi-Shinozaki, K.; Shinozaki, K.; Tran, L.-S.P. Differential gene expression in soybean leaf tissues at late developmental stages under drought stress revealed by genomewide transcriptome analysis. PloS ONE 2012, 7, e49522.

60. Formentin, E.; Sudiro, C.; Perin, G.; Riccadonna, S.; Barizza, E.; Baldoni, E.; Lavezzo, E.; Stevanato, P.; Sacchi, G.A.; Fontana, $\mathrm{P}$. Transcriptome and cell physiological analyses in different rice cultivars provide new insights into adaptive and salinity stress responses. Frontiers in Plant Science 2018, 9, 204.

61. Li, Z.; Hu, G.; Liu, X.; Zhou, Y.; Li, Y.; Zhang, X.; Yuan, X.; Zhang, Q.; Yang, D.; Wang, T. Transcriptome sequencing identified genes and gene ontologies associated with early freezing tolerance in maize. Frontiers in Plant Science 2016, 7, 1477. Abdel-Ghany, S.E.; Ullah, F.; Ben-Hur, A.; Reddy, A.S. Transcriptome analysis of drought-resistant and drought-sensitive sorghum (Sorghum bicolor) genotypes in response to peg-induced drought stress. International Journal of Molecular Sciences 2020, 21, 772 .

63. Yoo, Y.-H.; Nalini Chandran, A.K.; Park, J.-C.; Gho, Y.-S.; Lee, S.-W.; An, G.; Jung, K.-H. OsPhyB-mediating novel regulatory pathway for drought tolerance in rice root identified by a global RNA-Seq transcriptome analysis of rice genes in response to water deficiencies. Frontiers in Plant Science 2017, 8, 580. 
64. Hong, W.-J.; Jiang, X.; Ahn, H.R.; Choi, J.; Kim, S.-R.; Jung, K.-H. Systematic analysis of cold stress response and diurnal rhythm using transcriptome data in rice reveals the molecular networks related to various biological processes. International Journal of Molecular Sciences 2020, 21, 6872.

65. Hu, L.; Xie, Y.; Fan, S.; Wang, Z.; Wang, F.; Zhang, B.; Li, H.; Song, J.; Kong, L. Comparative analysis of root transcriptome profiles between drought-tolerant and susceptible wheat genotypes in response to water stress. Plant Science 2018, 272, 276293.

66. Winfield, M.O.; Lu, C.; Wilson, I.D.; Coghill, J.A.; Edwards, K.J. Cold-and light-induced changes in the transcriptome of wheat leading to phase transition from vegetative to reproductive growth. BMC Plant Biology 2009, 9, 1-14.

67. Kawaura, K.; Mochida, K.; Yamazaki, Y.; Ogihara, Y. Transcriptome analysis of salinity stress responses in common wheat using a 22k oligo-DNA microarray. Functional E Integrative Genomics 2006, 6, 132-142.

68. Wang, N.; Li, L.; Gao, W.; Wu, Y.; Yong, H.; Weng, J.; LI, M.-S.; Zhang, D.; Hao, Z.; Li, X. Transcriptomes of early developing tassels under drought stress reveal differential expression of genes related to drought tolerance in maize. Journal of Integrative Agriculture 2018, 17, 1276-1288.

69. Wang, M.; Wang, Y.; Zhang, Y.; Li, C.; Gong, S.; Yan, S.; Li, G.; Hu, G.; Ren, H.; Yang, J. Comparative transcriptome analysis of salt-sensitive and salt-tolerant maize reveals potential mechanisms to enhance salt resistance. Genes $\mathcal{E}$ Genomics 2019, 41, 781-801.

70. Janiak, A.; Kwasniewski, M.; Sowa, M.; Kuczyńska, A.; Mikołajczak, K.; Ogrodowicz, P.; Szarejko, I. Insights into barley root transcriptome under mild drought stress with an emphasis on gene expression regulatory mechanisms. International Journal of Molecular Sciences 2019, 20, 6139.

71. Hill, C.B.; Cassin, A.; Keeble-Gagnère, G.; Doblin, M.S.; Bacic, A.; Roessner, U. De novo transcriptome assembly and analysis of differentially expressed genes of two barley genotypes reveal root-zone-specific responses to salt exposure. Scientific Reports 2016, 6, 1-14.

72. Sun, X.; Zheng, H.; Li, J.; Liu, L.; Zhang, X.; Sui, N. Comparative transcriptome analysis reveals new lncRNAs responding to salt stress in sweet sorghum. Frontiers in Bioengineering and Biotechnology 2020, 8, 331.

73. Punia, H.; Tokas, J.; Bhadu, S.; Mohanty, A.K.; Rawat, P.; Malik, A. Proteome dynamics and transcriptome profiling in sorghum [Sorghum bicolor (L.) Moench] under salt stress. 3 Biotech 2020, 10, 1-10.

74. Atkinson, N.J.; Urwin, P.E. The interaction of plant biotic and abiotic stresses: from genes to the field. Journal of Experimental Botany 2012, 63, 3523-3543.

Bilgin, D.D.; Zavala, J.A.; Zhu, J.; Clough, S.J.; Ort, D.R.; DeLUCIA, E.H. Biotic stress globally downregulates photosynthesis genes. Plant, cell E environment 2010, 33, 1597-1613.

76. Garrett, K.A.; Dendy, S.P.; Frank, E.E.; Rouse, M.N.; Travers, S.E. Climate change effects on plant disease: genomes to ecosystems. Annu. Rev. Phytopathol. 2006, 44, 489-509.

Pan, Y.; Liu, Z.; Rocheleau, H.; Fauteux, F.; Wang, Y.; McCartney, C.; Ouellet, T. Transcriptome dynamics associated with resistance and susceptibility against Fusarium head blight in four wheat genotypes. BMC Genomics 2018, 19, 1-26.

Jeon, J.; Lee, G.-W.; Kim, K.-T.; Park, S.-Y.; Kim, S.; Kwon, S.; Huh, A.; Chung, H.; Lee, D.-Y.; Kim, C.-Y. Transcriptome profiling of the rice blast fungus Magnaporthe oryzae and its host Oryza sativa during infection. Molecular Plant-Microbe Interactions 2020, 33, 141-144.

79. Tariq, R.; Wang, C.; Qin, T.; Xu, F.; Tang, Y.; Gao, Y.; Ji, Z.; Zhao, K. Comparative transcriptome profiling of rice nearisogenic line carrying Xa23 under infection of Xanthomonas oryzae pv. oryzae. International Journal of Molecular Sciences 2018, $19,717$.

80. Zhang, J.; Chen, L.; Fu, C.; Wang, L.; Liu, H.; Cheng, Y.; Li, S.; Deng, Q.; Wang, S.; Zhu, J. Comparative transcriptome analyses of gene expression changes triggered by Rhizoctonia solani AG1 IA infection in resistant and susceptible rice varieties. Frontiers in Plant Science 2017, 8, 1422. 
81. Sharma, C.; Saripalli, G.; Kumar, S.; Gautam, T.; Kumar, A.; Rani, S.; Jain, N.; Prasad, P.; Raghuvanshi, S.; Jain, M. A study of transcriptome in leaf rust infected bread wheat involving seedling resistance gene Lr28. Functional Plant Biology 2018, 45, 1046-1064.

82. Hao, Y.; Wang, T.; Wang, K.; Wang, X.; Fu, Y.; Huang, L.; Kang, Z. Transcriptome analysis provides insights into the mechanisms underlying wheat plant resistance to stripe rust at the adult plant stage. PLoS ONE 2016, 11, e0150717.

83. Yu, Y.; Shi, J.; Li, X.; Liu, J.; Geng, Q.; Shi, H.; Ke, Y.; Sun, Q. Transcriptome analysis reveals the molecular mechanisms of the defense response to gray leaf spot disease in maize. BMC Genomics 2018, 19, 1-17.

84. Kebede, A.Z.; Johnston, A.; Schneiderman, D.; Bosnich, W.; Harris, L.J. Transcriptome profiling of two maize inbreds with distinct responses to Gibberella ear rot disease to identify candidate resistance genes. BMC Genomics 2018, 19, 1-12.

85. Ghorbani, A.; Izadpanah, K.; Dietzgen, R.G. Changes in maize transcriptome in response to maize Iranian mosaic virus infection. PLoS ONE 2018, 13, e0194592.

86. Sjokvist, E.; Lemcke, R.; Kamble, M.; Turner, F.; Blaxter, M.; Havis, N.H.; Lyngkjær, M.F.; Radutoiu, S. Dissection of Ramularia leaf spot disease by integrated analysis of barley and Ramularia collo-cygni transcriptome responses. Molecular Plant-Microbe Interactions 2019, 32, 176-193.

87. Liu, H.; Li, G.; Yang, X.; Kuijer, H.N.J.; Liang, W.; Zhang, D. Transcriptome profiling reveals phase-specific gene expression in the developing barley inflorescence. The Crop Journal 2020, 8, 71-86, doi:10.1016/j.cj.2019.04.005.

88. Shoaib, A.; Aldaoude, A.; Arabi, M.; Al-Shehadah, E.; Jawhar, M. Transcriptome profiling reveals distinct gene activations in barley responding to scald and spot blotch. Cereal Research Communications 2018, 46, 490-498.

89. Tan, L.; Chen, S.; Wang, T.; Dai, S. Proteomic insights into seed germination in response to environmental factors. Proteomics 2013, 13, 1850-1870.

90. Eldakak, M.; Milad, S.I.; Nawar, A.I.; Rohila, J.S. Proteomics: a biotechnology tool for crop improvement. Frontiers in Plant Science 2013, 4, 35.

91. Ashwin, N.; Barnabas, L.; Sundar, A.R.; Malathi, P.; Viswanathan, R.; Masi, A.; Agrawal, G.K.; Rakwal, R. Advances in proteomic technologies and their scope of application in understanding plant-pathogen interactions. Journal of Plant Biochemistry and Biotechnology 2017, 26, 371-386.

92. Anguraj Vadivel, A.K. Gel-based proteomics in plants: time to move on from the tradition. Frontiers in Plant Science 2015, 6, 369.

93. Tan, B.C.; Lim, Y.S.; Lau, S.-E. Proteomics in commercial crops: an overview. Journal of Proteomics 2017, 169, 176-188.

94. Lee, J.; Jiang, W.; Qiao, Y.; Cho, Y.I.; Woo, M.O.; Chin, J.H.; Kwon, S.W.; Hong, S.S.; Choi, I.Y.; Koh, H.J. Shotgun proteomic analysis for detecting differentially expressed proteins in the reduced culm number rice. Proteomics 2011, 11, 455-468.

95. Beckett, P. The basics of 2D DIGE. In Difference gel electrophoresis (DIGE), Springer: 2012; pp. 9-19.

96. Colignon, B.; Raes, M.; Dieu, M.; Delaive, E.; Mauro, S. Evaluation of three - dimensional gel electrophoresis to improve quantitative profiling of complex proteomes. Proteomics 2013, 13, 2077-2082.

97. Rabilloud, T. When 2 D is not enough, go for an extra dimension. Proteomics 2013, 13, 2065-2068.

98. Shiio, Y.; Aebersold, R. Quantitative proteome analysis using isotope-coded affinity tags and mass spectrometry. Nature protocols 2006, 1, 139.

99. Das, A.; Paudel, B.; Rohila, J.S. Potentials of proteomics in crop breeding. In Advances in plant breeding strategies: breeding, biotechnology and molecular tools, Springer: 2015; pp. 513-537.

100. Evans, C.; Noirel, J.; Ow, S.Y.; Salim, M.; Pereira-Medrano, A.G.; Couto, N.; Pandhal, J.; Smith, D.; Pham, T.K.; Karunakaran, E. An insight into iTRAQ: where do we stand now? Analytical and bioanalytical chemistry 2012, 404, 1011-1027.

101. Ong, S.-E.; Blagoev, B.; Kratchmarova, I.; Kristensen, D.B.; Steen, H.; Pandey, A.; Mann, M. Stable isotope labeling by amino acids in cell culture, SILAC, as a simple and accurate approach to expression proteomics. Molecular E Cellular Proteomics 2002, 1, 376-386. 
102. Mastrobuoni, G.; Irgang, S.; Pietzke, M.; Aßmus, H.E.; Wenzel, M.; Schulze, W.X.; Kempa, S. Proteome dynamics and early salt stress response of the photosynthetic organism Chlamydomonas reinhardtii. BMC Genomics 2012, 13, 1-13.

103. Liebler, D.C.; Zimmerman, L.J. Targeted quantitation of proteins by mass spectrometry. Biochemistry 2013, 52, $3797-3806$.

104. Jorrín - Novo, J.V.; Pascual, J.; Sánchez - Lucas, R.; Romero - Rodríguez, M.C.; Rodríguez - Ortega, M.J.; Lenz, C.; Valledor, L. Fourteen years of plant proteomics reflected in Proteomics: Moving from model species and 2DE - based approaches to orphan species and gel - free platforms. Proteomics 2015, 15, 1089-1112.

105. Wu, Y.; Mirzaei, M.; Pascovici, D.; Chick, J.M.; Atwell, B.J.; Haynes, P.A. Quantitative proteomic analysis of two different rice varieties reveals that drought tolerance is correlated with reduced abundance of photosynthetic machinery and increased abundance of ClpD1 protease. Journal of Proteomics 2016, 143, 73-82.

106. Gong, C.Y.; Li, Q.; Yu, H.T.; Wang, Z.; Wang, T. Proteomics insight into the biological safety of transgenic modification of rice as compared with conventional genetic breeding and spontaneous genotypic variation. Journal of Proteome Research $\mathbf{2 0 1 2}$, 11, 3019-3029.

107. Ji, Z.; Zeng, Y.; Liang, Y.; Qian, Q.; Yang, C. Proteomic dissection of the rice-Fusarium fujikuroi interaction and the correlation between the proteome and transcriptome under disease stress. BMC Genomics 2019, 20, 1-11.

108. Wang, Y.; Kim, S.G.; Wu, J.; Huh, H.H.; Lee, S.J.; Rakwal, R.; Kumar Agrawal, G.; Park, Z.Y.; Young Kang, K.; Kim, S.T. Secretome analysis of the rice bacterium Xanthomonas oryzae (Xoo) using in vitro and in planta systems. Proteomics 2013, 13, 1901-1912.

109. Hao, P.; Zhu, J.; Gu, A.; Lv, D.; Ge, P.; Chen, G.; Li, X.; Yan, Y. An integrative proteome analysis of different seedling organs in tolerant and sensitive wheat cultivars under drought stress and recovery. Proteomics 2015, 15, 1544-1563.

110. Kacem, N.; Mauro, S.; Muhovski, Y.; Delporte, F.; Renaut, J.; Djekoun, A.; Watillon, B. Diagonal two-dimensional electrophoresis (D-2DE): a new approach to study the effect of osmotic stress induced by polyethylene glycol in durum wheat (Triticum durum Desf.). Molecular Biology Reports 2016, 43, 897-909.

111. Maytalman, D.; Mert, Z.; Baykal, A.; Inan, C.; Gunel, A.; Hasançebi, S. Proteomic analysis of early responsive resistance proteins of wheat (Triticum aestivum) to yellow rust (Puccinia striiformis f. sp. tritici) using ProteomeLab PF2D. Plant Omics 2013.

112. Day, J.; Gietz, R.D.; Rampitsch, C. Proteome changes induced by Pyrenophora tritici-repentis ToxA in both insensitive and sensitive wheat indicate senescence-like signaling. Proteome Science 2015, 13, 1-10.

113. Cui, D.; Wu, D.; Liu, J.; Li, D.; Xu, C.; Li, S.; Li, P.; Zhang, H.; Liu, X.; Jiang, C. Proteomic analysis of seedling roots of two maize inbred lines that differ significantly in the salt stress response. PLoS One 2015, 10, e0116697.

114. Li, G.; Gao, J.; Peng, H.; Shen, Y.; Ding, H.; Zhang, Z.; Pan, G.; Lin, H. Proteomic changes in maize as a response to heavy metal (lead) stress revealed by iTRAQ quantitative proteomics. Genetics and Molecular Research 2016, 15, 10.4238.

115. Mohammadi, M.; Anoop, V.; Gleddie, S.; Harris, L.J. Proteomic profiling of two maize inbreds during early gibberella ear rot infection. Proteomics 2011, 11, 3675-3684.

116. Yue, R.; Lu, C.; Han, X.; Guo, S.; Yan, S.; Liu, L.; Fu, X.; Chen, N.; Guo, X.; Chi, H. Comparative proteomic analysis of maize (Zea mays L.) seedlings under rice black-streaked dwarf virus infection. BMC Plant Biology 2018, 18, 1-11.

117. Ashoub, A.; Baeumlisberger, M.; Neupaertl, M.; Karas, M.; Brüggemann, W. Characterization of common and distinctive adjustments of wild barley leaf proteome under drought acclimation, heat stress and their combination. Plant Molecular Biology 2015, 87, 459-471.

118. Mostek, A.; Börner, A.; Weidner, S. Comparative proteomic analysis of $\beta$-aminobutyric acid-mediated alleviation of salt stress in barley. Plant Physiology and Biochemistry 2016, 99, 150-161.

119. Bernardo, L.; Prinsi, B.; Negri, A.S.; Cattivelli, L.; Espen, L.; Valè, G. Proteomic characterization of the Rph15 barley resistance gene-mediated defence responses to leaf rust. BMC Genomics 2012, 13, 1-16.

120. Eggert, K.; Pawelzik, E. Proteome analysis of Fusarium head blight in grains of naked barley (Hordeum vulgare subsp. nudum). Proteomics 2011, 11, 972-985. 
121. Pennington, H.G.; Gheorghe, D.M.; Damerum, A.; Pliego, C.; Spanu, P.D.; Cramer, R.; Bindschedler, L.V. Interactions between the powdery mildew effector BEC1054 and barley proteins identify candidate host targets. Journal of Proteome Research 2016, 15, 826-839.

122. Roy, S.K.; Cho, S.-W.; Kwon, S.J.; Kamal, A.H.M.; Kim, S.-W.; Oh, M.-W.; Lee, M.-S.; Chung, K.-Y.; Xin, Z.; Woo, S.-H. Morpho-physiological and proteome level responses to cadmium stress in sorghum. PLoS ONE 2016, 11, e0150431.

123. Jedmowski, C.; Ashoub, A.; Beckhaus, T.; Berberich, T.; Karas, M.; Brüggemann, W. Comparative analysis of Sorghum bicolor proteome in response to drought stress and following recovery. International Journal of Proteomics 2014, 2014.

124. Jadhav, K.; Ranjani, R.V.; Senthil, N.; Arulkumar, N.; Tamilarasi, P.; Sumathi, K.; Ganesan, K.; Paranidharan, V.; Raveendran, M.; Kim, G.S. Proteomic Analysis of a Compatible Interaction between Sorghum Downy Mildew Pathogen (Peronosclerospora sorghi) and Maize (Zea mays L.). Int. J. Curr. Microbiol. App. Sci 2018, 7, 653-670.

125. del Toro, N.; Reisinger, F.; Foster, J.M.; Contell, J.; Fabregat, A.; Safont, P.R.; Hermjakob, H.; Vizcaíno, J.A. PRIDE Proteomes: a condensed view of the plethora of public proteomics data available in the PRIDE repository. DILS 2014 2014, 21.

126. Kusebauch, U.; Deutsch, E.W.; Campbell, D.S.; Sun, Z.; Farrah, T.; Moritz, R.L. Using PeptideAtlas, SRMAtlas, and PASSEL: comprehensive resources for discovery and targeted proteomics. Current Protocols in Bioinformatics 2014, 46, 13.25. 11-13.25. 28.

127. Sun, Q.; Zybailov, B.; Majeran, W.; Friso, G.; Olinares, P.D.B.; Van Wijk, K.J. PPDB, the plant proteomics database at Cornell. Nucleic acids research 2009, 37, D969-D974.

128. Joshi, H.J.; Christiansen, K.M.; Fitz, J.; Cao, J.; Lipzen, A.; Martin, J.; Smith-Moritz, A.M.; Pennacchio, L.A.; Schackwitz, W.S.; Weigel, D. 1001 Proteomes: a functional proteomics portal for the analysis of Arabidopsis thaliana accessions. Bioinformatics 2012, 28, 1303-1306.

129. Sapkota, A.; Liu, X.; Zhao, X.-M.; Cao, Y.; Liu, J.; Liu, Z.-P.; Chen, L. DIPOS: database of interacting proteins in Oryza sativa. Molecular BioSystems 2011, 7, 2615-2621.

130. Hirsch-Hoffmann, M.; Gruissem, W.; Baerenfaller, K. pep2pro: the high-throughput proteomics data processing, analysis, and visualization tool. Frontiers in plant science 2012, 3, 123.

131. Braun, H.-P.; Senkler, M. Functional annotation of 2D protein maps: the GelMap portal. Frontiers in Plant Science $2012,3,87$.

132. Fan, J.; Mohareb, F.; Jones, A.M.; Bessant, C. MRMaid: the SRM assay design tool for Arabidopsis and other species. Frontiers in Plant Science 2012, 3, 164.

133. Farrah, T.; Deutsch, E.W.; Kreisberg, R.; Sun, Z.; Campbell, D.S.; Mendoza, L.; Kusebauch, U.; Brusniak, M.Y.; Hüttenhain, R.; Schiess, R. PASSEL: The Peptide Atlas SRM experiment library. Proteomics 2012, 12, 1170-1175.

134. Baslam, M.; Mitsui, T. Proteomic for quality: mining the proteome as a strategy to elucidate the protein complex applied for quality improvement. In The Future of Rice Demand: Quality Beyond Productivity, Springer: 2020; pp. 473-494.

135. Deborde, C.; Moing, A.; Roch, L.; Jacob, D.; Rolin, D.; Giraudeau, P. Plant metabolism as studied by NMR spectroscopy. Progress in Nuclear Magnetic Resonance Spectroscopy 2017, 102, 61-97.

136. Khakimov, B.; Bak, S.; Engelsen, S.B. High-throughput cereal metabolomics: Current analytical technologies, challenges and perspectives. Journal of Cereal Science 2014, 59, 393-418.

137. Ibarra-Estrada, E.; Soto-Hernández, R.M.; Palma-Tenango, M. Metabolomics as a tool in agriculture. Metabolomics: Fundamentals and Applications 2016, 148-168.

138. Balmer, D.; Flors, V.; Glauser, G.; Mauch-Mani, B. Metabolomics of cereals under biotic stress: current knowledge and techniques. Frontiers in Plant Science 2013, 4, 82.

139. Piasecka, A.; Kachlicki, P.; Stobiecki, M. Analytical methods for detection of plant metabolomes changes in response to biotic and abiotic stresses. International Journal of Molecular Sciences 2019, 20, 379.

140. Wen, W.; Li, D.; Li, X.; Gao, Y.; Li, W.; Li, H.; Liu, J.; Liu, H.; Chen, W.; Luo, J. Metabolome-based genome-wide association study of maize kernel leads to novel biochemical insights. Nature Communications 2014, 5, 1-10. 
141. Vuckovic, D. Current trends and challenges in sample preparation for global metabolomics using liquid chromatographymass spectrometry. Analytical and Bioanalytical Chemistry 2012, 403, 1523-1548.

142. Wu, X.; Li, N.; Li, H.; Tang, H. An optimized method for NMR-based plant seed metabolomic analysis with maximized polar metabolite extraction efficiency, signal-to-noise ratio, and chemical shift consistency. Analyst 2014, 139, $1769-1778$.

143. Kim, H.K.; Verpoorte, R. Sample preparation for plant metabolomics. Phytochemical Analysis: An International Journal of Plant Chemical and Biochemical Techniques 2010, 21, 4-13.

144. Casartelli, A.; Riewe, D.; Hubberten, H.M.; Altmann, T.; Hoefgen, R.; Heuer, S. Exploring traditional aus-type rice for metabolites conferring drought tolerance. Rice 2018, 11, 1-16.

145. Cao, D.; Lutz, A.; Hill, C.B.; Callahan, D.L.; Roessner, U. A quantitative profiling method of phytohormones and other metabolites applied to barley roots subjected to salinity stress. Frontiers in Plant Science 2017, 7, 2070.

146. Zhang, W.; Ramautar, R. CE - MS for metabolomics: Developments and applications in the period 2018-2020. Electrophoresis 2020.

147. Jones, O.A.; Maguire, M.L.; Griffin, J.L.; Jung, Y.-H.; Shibato, J.; Rakwal, R.; Agrawal, G.K.; Jwa, N.-S. Using metabolic profiling to assess plant-pathogen interactions: an example using rice (Oryza sativa) and the blast pathogen Magnaporthe grisea. European Journal of Plant Pathology 2011, 129, 539-554.

148. Witt, S.; Galicia, L.; Lisec, J.; Cairns, J.; Tiessen, A.; Araus, J.L.; Palacios-Rojas, N.; Fernie, A.R. Metabolic and phenotypic responses of greenhouse-grown maize hybrids to experimentally controlled drought stress. Molecular Plant 2012, 5, $401-417$.

149. Zhao, Y.-Y.; Wu, S.-P.; Liu, S.; Zhang, Y.; Lin, R.-C. Ultra-performance liquid chromatography-mass spectrometry as a sensitive and powerful technology in lipidomic applications. Chemico-Biological Interactions 2014, 220, 181-192.

150. Suharti, W.S.; Nose, A.; Zheng, S.-H. Metabolomic study of two rice lines infected by Rhizoctonia solani in negative ion mode by CE/TOF-MS. Journal of Plant Physiology 2016, 206, 13-24.

151. Karre, S.; Kumar, A.; Dhokane, D.; Kushalappa, A.C. Metabolo-transcriptome profiling of barley reveals induction of chitin elicitor receptor kinase gene (HvCERK1) conferring resistance against Fusarium graminearum. Plant Molecular Biology 2017, 93, 247-267.

152. Benincasa, P.; D'Amato, R.; Falcinelli, B.; Troni, E.; Fontanella, M.C.; Frusciante, S.; Guiducci, M.; Beone, G.M.; Businelli, D.; Diretto, G. Grain endogenous selenium and moderate salt stress work as synergic elicitors in the enrichment of bioactive compounds in maize sprouts. Agronomy 2020, 10, 735.

153. Kessler, N.; Neuweger, H.; Bonte, A.; Langenkämper, G.; Niehaus, K.; Nattkemper, T.W.; Goesmann, A. MeltDB 2.0advances of the metabolomics software system. Bioinformatics 2013, 29, 2452-2459.

154. Chun, H.; Keleş, S. Sparse partial least squares regression for simultaneous dimension reduction and variable selection. Journal of the Royal Statistical Society: Series B (Statistical Methodology) 2010, 72, 3-25.

155. Xu, Y.; Goodacre, R. Multiblock principal component analysis: an efficient tool for analyzing metabolomics data which contain two influential factors. Metabolomics 2012, 8, 37-51.

156. Afendi, F.M.; Okada, T.; Yamazaki, M.; Hirai-Morita, A.; Nakamura, Y.; Nakamura, K.; Ikeda, S.; Takahashi, H.; Altaf-UlAmin, M.; Darusman, L.K. KNApSAcK family databases: integrated metabolite-plant species databases for multifaceted plant research. Plant and Cell Physiology 2012, 53, e1-e1.

157. Kanehisa, M. KEGG bioinformatics resource for plant genomics and metabolomics. In Plant Bioinformatics, Springer: 2016; pp. 55-70.

158. Pavli, O.I.; Vlachos, C.E.; Kalloniati, C.; Flemetakis, E.; Skaracis, G.N. Metabolite profiling reveals the effect of drought on sorghum ('Sorghum bicolor'L. Moench) metabolism. Plant Omics 2013, 6.

159. Matsuda, F.; Okazaki, Y.; Oikawa, A.; Kusano, M.; Nakabayashi, R.; Kikuchi, J.; Yonemaru, J.I.; Ebana, K.; Yano, M.; Saito, K. Dissection of genotype-phenotype associations in rice grains using metabolome quantitative trait loci analysis. The Plant Journal 2012, 70, 624-636. 
160. Chen, W.; Gao, Y.; Xie, W.; Gong, L.; Lu, K.; Wang, W.; Li, Y.; Liu, X.; Zhang, H.; Dong, H. Genome-wide association analyses provide genetic and biochemical insights into natural variation in rice metabolism. Nature genetics 2014, 46, 714-721.

161. Brunetti, C.; George, R.M.; Tattini, M.; Field, K.; Davey, M.P. Metabolomics in plant environmental physiology. Journal of Experimental Botany 2013, 64, 4011-4020.

162. Misra, B.B.; Assmann, S.M.; Chen, S. Plant single-cell and single-cell-type metabolomics. Trends in Plant Science 2014, 19, 637-646.

163. Sun, M.; Yang, Z.; Wawrik, B. Metabolomic fingerprints of individual algal cells using the single-probe mass spectrometry technique. Frontiers in Plant Science 2018, 9, 571.

164. Barding Jr, G.A.; Fukao, T.; Béni, S.; Bailey-Serres, J.; Larive, C.K. Differential metabolic regulation governed by the rice SUB1A gene during submergence stress and identification of alanylglycine by 1H NMR spectroscopy. Journal of Proteome Research 2012, 11, 320-330.

165. Yang, M.; Yang, J.; Su, L.; Sun, K.; Li, D.; Liu, Y.; Wang, H.; Chen, Z.; Guo, T. Metabolic profile analysis and identification of key metabolites during rice seed germination under low-temperature stress. Plant Science 2019, 289, 110282.

166. Zhang, Y.; Ma, X.-m.; Wang, X.-c.; Liu, J.-h.; Huang, B.-y.; Guo, X.-y.; Xiong, S.-p.; La, G.-X. UPLC-QTOF analysis reveals metabolomic changes in the flag leaf of wheat (Triticum aestivum L.) under low-nitrogen stress. Plant Physiology and Biochemistry 2017, 111, 30-38.

167. Gavaghan, C.L.; Li, J.V.; Hadfield, S.T.; Hole, S.; Nicholson, J.K.; Wilson, I.D.; Howe, P.W.; Stanley, P.D.; Holmes, E. Application of NMR - based metabolomics to the investigation of salt stress in maize (Zea mays). Phytochemical Analysis 2011, 22, 214-224.

168. Amiour, N.; Imbaud, S.; Clément, G.; Agier, N.; Zivy, M.; Valot, B.; Balliau, T.; Armengaud, P.; Quilleré, I.; Cañas, R. The use of metabolomics integrated with transcriptomic and proteomic studies for identifying key steps involved in the control of nitrogen metabolism in crops such as maize. Journal of Experimental Botany 2012, 63, 5017-5033.

169. Swarcewicz, B.; Sawikowska, A.; Marczak, Ł.; Łuczak, M.; Ciesiołka, D.; Krystkowiak, K.; Kuczyńska, A.; PiślewskaBednarek, M.; Krajewski, P.; Stobiecki, M. Effect of drought stress on metabolite contents in barley recombinant inbred line population revealed by untargeted GC-MS profiling. Acta Physiologiae Plantarum 2017, 39, 1-16.

170. Sheflin, A.M.; Chiniquy, D.; Yuan, C.; Goren, E.; Kumar, I.; Braud, M.; Brutnell, T.; Eveland, A.L.; Tringe, S.; Liu, P. Metabolomics of sorghum roots during nitrogen stress reveals compromised metabolic capacity for salicylic acid biosynthesis. Plant Direct 2019, 3, e00122.

171. Vincent, D.; Du Fall, L.A.; Livk, A.; Mathesius, U.; Lipscombe, R.J.; Oliver, R.P.; Friesen, T.L.; Solomon, P.S. A functional genomics approach to dissect the mode of action of the Stagonospora nodorum effector protein SnToxA in wheat. Molecular Plant Pathology 2012, 13, 467-482.

172. Ciasca, B.; Lanubile, A.; Marocco, A.; Pascale, M.; Logrieco, A.F.; Lattanzio, V.M. Application of an Integrated and Open Source Workflow for LC-HRMS Plant Metabolomics Studies. Case-Control Study: Metabolic Changes of Maize in Response to Fusarium verticillioides Infection. Frontiers in Plant Science 2020, 11, 664.

173. Kumaraswamy, K.G.; Kushalappa, A.C.; Choo, T.M.; Dion, Y.; Rioux, S. Mass spectrometry based metabolomics to identify potential biomarkers for resistance in barley against fusarium head blight (Fusarium graminearum). Journal of Chemical Ecology 2011, 37, 846-856.

174. Mareya, C.R.; Tugizimana, F.; Piater, L.A.; Madala, N.E.; Steenkamp, P.A.; Dubery, I.A. Untargeted metabolomics reveal defensome-related metabolic reprogramming in Sorghum bicolor against infection by Burkholderia andropogonis. Metabolites 2019, 9, 8 .

175. Anderegg, J.; Hund, A.; Karisto, P.; Mikaberidze, A. In-Field Detection and Quantification of Septoria tritici Blotch in Diverse Wheat Germplasm Using Spectral-Temporal Features. Frontiers in Plant Science 2019, 10, 1355.

176. White, J.W.; Conley, M.M. A flexible, low - cost cart for proximal sensing. Crop Science 2013, 53, 1646-1649. 
177. Sirault, X.R.; James, R.A.; Furbank, R.T. A new screening method for osmotic component of salinity tolerance in cereals using infrared thermography. Functional Plant Biology 2009, 36, 970-977.

178. Crain, J.; Mondal, S.; Rutkoski, J.; Singh, R.P.; Poland, J. Combining high - throughput phenotyping and genomic information to increase prediction and selection accuracy in wheat breeding. The plant genome 2018, 11, 170043.

179. Singh, A.; Ganapathysubramanian, B.; Singh, A.K.; Sarkar, S. Machine learning for high-throughput stress phenotyping in plants. Trends in Plant Science 2016, 21, 110-124.

180. Sandhu, K.S.; Mihalyov, P.D.; Lewiwn, M.J.; Pumphre, y.M.O.; Carter, A.H. Combining genomic and phenomic information for predicting grain protein content and grain yield in spring wheat. Frontiers in Plant Science 2021, 12, doi:10.3389/fpls.2021.613300.

181. Duan, L.; Han, J.; Guo, Z.; Tu, H.; Yang, P.; Zhang, D.; Fan, Y.; Chen, G.; Xiong, L.; Dai, M. Novel digital features discriminate between drought resistant and drought sensitive rice under controlled and field conditions. Frontiers in Plant Science 2018, $9,492$.

182. Busemeyer, L.; Mentrup, D.; Möller, K.; Wunder, E.; Alheit, K.; Hahn, V.; Maurer, H.P.; Reif, J.C.; Würschum, T.; Müller, J. BreedVision-A multi-sensor platform for non-destructive field-based phenotyping in plant breeding. Sensors 2013, 13, 2830-2847.

183. Jansen, M.; Gilmer, F.; Biskup, B.; Nagel, K.A.; Rascher, U.; Fischbach, A.; Briem, S.; Dreissen, G.; Tittmann, S.; Braun, S. Simultaneous phenotyping of leaf growth and chlorophyll fluorescence via GROWSCREEN FLUORO allows detection of stress tolerance in Arabidopsis thaliana and other rosette plants. Functional Plant Biology 2009, 36, 902-914.

184. Fanourakis, D.; Briese, C.; Max, J.F.; Kleinen, S.; Putz, A.; Fiorani, F.; Ulbrich, A.; Schurr, U. Rapid determination of leaf area and plant height by using light curtain arrays in four species with contrasting shoot architecture. Plant Methods 2014, 10, 111.

185. Voorend, W.; Lootens, P.; Nelissen, H.; Roldán-Ruiz, I.; Inzé, D.; Muylle, H. LEAF-E: a tool to analyze grass leaf growth using function fitting. Plant Methods 2014, 10, 1-13.

186. Granier, C.; Aguirrezabal, L.; Chenu, K.; Cookson, S.J.; Dauzat, M.; Hamard, P.; Thioux, J.J.; Rolland, G.; Bouchier Combaud, S.; Lebaudy, A. PHENOPSIS, an automated platform for reproducible phenotyping of plant responses to soil water deficit in Arabidopsis thaliana permitted the identification of an accession with low sensitivity to soil water deficit. New Phytologist 2006, 169, 623-635.

187. Rousseau, C.; Hunault, G.; Gaillard, S.; Bourbeillon, J.; Montiel, G.; Simier, P.; Campion, C.; Jacques, M.-A.; Belin, E.; Boureau, T. Phenoplant: a web resource for the exploration of large chlorophyll fluorescence image datasets. Plant Methods 2015, 11, $1-12$.

188. Flood, P.J.; Kruijer, W.; Schnabel, S.K.; van der Schoor, R.; Jalink, H.; Snel, J.F.; Harbinson, J.; Aarts, M.G. Phenomics for photosynthesis, growth and reflectance in Arabidopsis thaliana reveals circadian and long-term fluctuations in heritability. Plant Methods 2016, 12, 1-14.

189. Friedli, M.; Kirchgessner, N.; Grieder, C.; Liebisch, F.; Mannale, M.; Walter, A. Terrestrial 3D laser scanning to track the increase in canopy height of both monocot and dicot crop species under field conditions. Plant Methods 2016, 12, 1-15.

190. Greenham, K.; Lou, P.; Remsen, S.E.; Farid, H.; McClung, C.R. TRiP: Tracking Rhythms in Plants, an automated leaf movement analysis program for circadian period estimation. Plant Methods 2015, 11, 1-11.

191. Zaman-Allah, M.; Vergara, O.; Araus, J.; Tarekegne, A.; Magorokosho, C.; Zarco-Tejada, P.; Hornero, A.; Albà, A.H.; Das, B.; Craufurd, P. Unmanned aerial platform-based multi-spectral imaging for field phenotyping of maize. Plant Methods 2015, 11, 1-10.

192. Wahabzada, M.; Mahlein, A.-K.; Bauckhage, C.; Steiner, U.; Oerke, E.-C.; Kersting, K. Metro maps of plant disease dynamics - automated mining of differences using hyperspectral images. PLoS ONE 2015, 10, e0116902.

193. Zhou, R.-Q.; Jin, J.-J.; Li, Q.-M.; Su, Z.-Z.; Yu, X.-J.; Tang, Y.; Luo, S.-M.; He, Y.; Li, X.-L. Early detection of Magnaporthe oryzaeinfected barley leaves and lesion visualization based on hyperspectral imaging. Frontiers in Plant Science 2019, 9, 1962. 
194. Becker, E.; Schmidhalter, U. Evaluation of yield and drought using active and passive spectral sensing systems at the reproductive stage in wheat. Frontiers in Plant Science 2017, 8, 379.

195. Behmann, J.; Schmitter, P.; Steinrücken, J.; Plümer, L. Ordinal classification for efficient plant stress prediction in hyperspectral data. International Archives of the Photogrammetry, Remote Sensing \& Spatial Information Sciences 2014.

196. Onoyama, H.; Ryu, C.; Suguri, M.; Iida, M. Potential of hyperspectral imaging for constructing a year-invariant model to estimate the nitrogen content of rice plants at the panicle initiation stage. IFAC Proceedings Volumes 2013, 46, $219-224$.

197. Deery, D.M.; Rebetzke, G.J.; Jimenez-Berni, J.A.; James, R.A.; Condon, A.G.; Bovill, W.D.; Hutchinson, P.; Scarrow, J.; Davy, R.; Furbank, R.T. Methodology for high-throughput field phenotyping of canopy temperature using airborne thermography. Frontiers in Plant Science 2016, 7, 1808.

198. Kefauver, S.C.; Vicente, R.; Vergara-Díaz, O.; Fernandez-Gallego, J.A.; Kerfal, S.; Lopez, A.; Melichar, J.P.; Serret Molins, M.D.; Araus, J.L. Comparative UAV and field phenotyping to assess yield and nitrogen use efficiency in hybrid and conventional barley. Frontiers in Plant Science 2017, 8, 1733.

199. Yao, H.; Hruska, Z.; Kincaid, R.; Brown, R.L.; Bhatnagar, D.; Cleveland, T.E. Detecting maize inoculated with toxigenic and atoxigenic fungal strains with fluorescence hyperspectral imagery. Biosystems Engineering 2013, 115, 125-135.

200. Al-Tamimi, N.; Brien, C.; Oakey, H.; Berger, B.; Saade, S.; Ho, Y.S.; Schmöckel, S.M.; Tester, M.; Negrão, S. Salinity tolerance loci revealed in rice using high-throughput non-invasive phenotyping. Nature Communications 2016, 7, 1-11.

201. Vigneau, N.; Ecarnot, M.; Rabatel, G.; Roumet, P. Potential of field hyperspectral imaging as a non destructive method to assess leaf nitrogen content in Wheat. Field Crops Research 2011, 122, 25-31.

202. Behmann, J.; Steinrücken, J.; Plümer, L. Detection of early plant stress responses in hyperspectral images. ISPRS Journal of Photogrammetry and Remote Sensing 2014, 93, 98-111.

203. Zhang, L.; Zhang, H.; Niu, Y.; Han, W. Mapping maize water stress based on UAV multispectral remote sensing. Remote Sensing 2019, 11, 605.

204. Guerrero, J.M.; Pajares, G.; Montalvo, M.; Romeo, J.; Guijarro, M. Support vector machines for crop/weeds identification in maize fields. Expert Systems with Applications 2012, 39, 11149-11155.

205. Wang, X.; Singh, D.; Marla, S.; Morris, G.; Poland, J. Field-based high-throughput phenotyping of plant height in sorghum using different sensing technologies. Plant Methods 2018, 14, 1-16.

206. Spindel, J.E.; Dahlberg, J.; Colgan, M.; Hollingsworth, J.; Sievert, J.; Staggenborg, S.H.; Hutmacher, R.; Jansson, C.; Vogel, J.P. Association mapping by aerial drone reveals 213 genetic associations for Sorghum bicolor biomass traits under drought. BMC Genomics 2018, 19, 1-18.

207. Kobayashi, T.; Kanda, E.; Kitada, K.; Ishiguro, K.; Torigoe, Y. Detection of rice panicle blast with multispectral radiometer and the potential of using airborne multispectral scanners. Phytopathology 2001, 91, 316-323.

208. Sirisomboon, C.D.; Putthang, R.; Sirisomboon, P. Application of near infrared spectroscopy to detect aflatoxigenic fungal contamination in rice. Food Control 2013, 33, 207-214.

209. Zhang, D.; Zhou, X.; Zhang, J.; Lan, Y.; Xu, C.; Liang, D. Detection of rice sheath blight using an unmanned aerial system with high-resolution color and multispectral imaging. PLOS ONE 2018, 13, e0187470.

210. Shahin, M.A.; Symons, S.J. Detection of Fusarium damaged kernels in Canada Western Red Spring wheat using visible/nearinfrared hyperspectral imaging and principal component analysis. Computers and Electronics in Agriculture 2011, 75, 107-112.

211. Zhang, X.; Han, L.; Dong, Y.; Shi, Y.; Huang, W.; Han, L.; González-Moreno, P.; Ma, H.; Ye, H.; Sobeih, T. A deep learningbased approach for automated yellow rust disease detection from high-resolution hyperspectral UAV images. Remote Sensing 2019, 11, 1554.

212. DeChant, C.; Wiesner-Hanks, T.; Chen, S.; Stewart, E.L.; Yosinski, J.; Gore, M.A.; Nelson, R.J.; Lipson, H. Automated identification of northern leaf blight-infected maize plants from field imagery using deep learning. Phytopathology 2017, 107, $1426-1432$. 
213. Loladze, A.; Rodrigues Jr, F.A.; Toledo, F.; San Vicente, F.; Gérard, B.; Boddupalli, M.P. Application of remote sensing for phenotyping tar spot complex resistance in maize. Frontiers in Plant Science 2019, 10, 552.

214. Thomas, S.; Behmann, J.; Steier, A.; Kraska, T.; Muller, O.; Rascher, U.; Mahlein, A.-K. Quantitative assessment of disease severity and rating of barley cultivars based on hyperspectral imaging in a non-invasive, automated phenotyping platform. Plant Methods 2018, 14, 1-12.

215. Sandhu, K.S.; Lozada, D.N.; Zhang, Z.; Pumphrey, M.O.; Carter, A.H. Deep learning for predicting complex traits in spring wheat breeding program. Frontiers in Plant Science 2020, 11, 2084. 